Review

\title{
Interface Reactions and Synthetic Reaction of Composite Systems
}

\author{
Joon Sik Park * and Jeong Min Kim \\ Division of Advanced Engineering Materials, Hanbat National University, Daejeon, 305-719 Korea; \\ E-Mail: jmk7475@hanbat.ac.kr (J.M.K.) \\ * Author to whom correspondence should be addressed; E-Mail: jsphb@hanbat.ac.kr.
}

Received: 11 November 2009; in revised form: 29 December 2009 / Accepted: 4 January 2010 / Published: 8 January 2010

\begin{abstract}
Interface reactions in composite systems often determine their overall properties, since product phases usually formed at interfaces during composite fabrication processing make up a large portion of the composites. Since most composite materials represent a ternary or higher order materials system, many studies have focused on analyses of diffusion phenomena and kinetics in multicomponent systems. However, the understanding of the kinetic behavior increases the complexity, since the kinetics of each component during interdiffusion reactions need to be defined for interpreting composite behaviors. From this standpoint, it is important to clarify the interface reactions for producing compatible interfaces with desired product phases. A thermodynamic evaluation such as a chemical potential of involving components can provide an understanding of the diffusion reactions, which govern diffusion pathways and product phase formation. A strategic approach for designing compatible interfaces is discussed in terms of chemical potential diagrams and interface morphology, with some material examples.
\end{abstract}

Keywords: reactive diffusion; biased reaction; chemical potential

\section{Introduction}

Interdiffusion reactions often occur for two phase reinforced metal matrix composite systems, and the limited availability of components restricts potential combinations and successful compatibility. The constraints often lead to diffusion barrier coatings, when selected materials possess superior 
properties. While the diffusion barrier coating strategy can be effective, it adds complexity to the overall processing and can represent a weak point in the system; especially when the large amount of interfacial area that must be covered without any flaws is considered [1-3]. Required to serve multifunctional purposes, a composite is usually a complex system of multiphase materials. In a composite with a $30 \%$ volume fraction fibers with a diameter of $10 \mu \mathrm{m}$ the matrix and reinforcement interfacial areas can approach $10^{3} \mathrm{~cm}^{2} / \mathrm{cm}^{3}$ so that a large amount of interfacial area exists for reactions [4], and consequently composites behave as an interfacial material, because their processing and performance are dominated by the characteristics of internal interfaces [1-7]. From this perspective, an in situ processing approach is to design the composite members for intentional reactions to yield a final state of a thermodynamically compatible system in which both an initial matrix and reinforcing materials undergo compositional and structural changes to yield a final combination, at least for the local interface area [4].

When composite members experience compositional changes, intermediate phases are usually produced, and the formation of these intermediate phases is dictated by a consideration of multicomponent phase equilibria and diffusion pathways [8]. The properties of the produced intermediate phases provide a critical factor for determining the composite's properties. In this regard, the reliable prediction of the diffusion path, including initial experimental data, is necessary to achieve in situ an optimized composite. Furthermore, the accumulated data and an effective strategy for controlling interface reactions can extend useful fields such as packaging and/or coating process. Several studies have concentrated on the analysis of diffusion phenomena in multi-component systems [9]. While basic diffusion analyses have been developed, an effective strategy to control the diffusion pathway has not been well-developed. If the reaction between matrix and reinforcement materials does not yield a preferred phase, the unwanted diffusion path should be changed to yield a desired phase sequence. In reality, this objective must be achieved by analyzing the interface reactions. While controlling the diffusion pathway is attractive, the designed diffusion pathway may not be stable, so that it is worthwhile to investigate the thermodynamic stability and kinetics of the product phases.

$\mathrm{SiC}$ is one attractive material with superior properties such as corrosion resistance, high strength and metallization [10-12]. A number of studies on the SiC-Metal interface reactions have been reported and include investigations on the thermal compatibility and/or the solid state reactions [13-18]. The reaction product sequence and interface morphology in SiC/metal reactions depend mainly on the contact materials. The products of an SiC/Ni reaction, for example, show a periodic morphology composed of alternating carbon and silicides [19,20]; in contrast, the products of the an $\mathrm{SiC} / \mathrm{Cr}$ reaction reveal planar layers of carbides and silicides [21]. For the SiC/metal reactions, the irregular morphology of product phases with complex kinetics during interdiffusion reactions has caused a difficulties in understanding the kinetic behavior of SiC/metal. Even though the estimation of kinetic values is well treated, the diffusion coefficients necessary for complete analyses are generally unavailable. Furthermore, they require four diffusion coefficients for each phase and they are variable with composition at a planar shape interface [9].

The restriction requires a semi-empirical estimation that may be generally applicable to useful systems, which does not limit a complex calculation nor does present phenomenological explanations. In fact, since the produced phase during interdiffusion reactions (diffusion pathway) can determine the global property of materials such as composites, multilayers or coatings, the clear identification of 
developed phases is crucial for optimization of materials' properties. In this perspective, chemical potentials of involving components may provide an insight for understanding the diffusion pathways during interdiffusion reactions.

For the current review, a graphical methodology for constructing chemical potential diagrams of ternary systems is presented for components with a limited solubility. At the same time, an engineering concept for achieving stable interfaces in a kinetic bound is discussed in terms of additional layer selection by controlling diffusion pathways under the examination of component chemical potentials for selected Ti-Al-Si and $\mathrm{SiC} /$ metal systems.

Intermetallic compounds such as the $\mathrm{TiAl}$ and $\mathrm{Ti}_{3} \mathrm{Al}$ phases in the binary $\mathrm{Ti}-\mathrm{Al}$ system have shown favorable properties and provide a potential to increase their toughness by an addition of other elements. They have been studied for the replacement of high temperature materials by producing composites composed of soft or hard reinforcement materials [22]. The Ti-Si system is another candidate for high temperature structural materials, because several high temperature intermetallics are present in the system. Moreover, the system includes the $\mathrm{Ti}_{5} \mathrm{Si}_{3}$ phase as a potential reinforcement material, because its melting temperature is $2,130{ }^{\circ} \mathrm{C}$ and the compression strength $(0.2 \%$ offset strength) has been reported up to $1,050 \mathrm{MPa}$ at 1,273 K [23,24]. Therefore, the ternary Ti-Si-Al system offers potentially useful properties for high temperature applications.

In this review, special attention has been given to analysis and control of the interface reactions and to develop strategies for the selected ternary model systems such as Si-C-Metal and/or Ti-Al-Si system. The identification and controlling reaction pathways have been examined by concentrating on the phase evolution, and kinetic and thermodynamic stability in terms of the relevant chemical potential variations.

\section{Chemical Potential Diagrams of Ternary Systems}

Since the diffusion path and phase sequence can be affected by the chemical potential changes during a reaction, it is important to analyze the chemical potential variation of each component. One method to understand a diffusion path is based upon the stability diagram concept proposed by van Loo [25]. Generally, the stability diagram represents an activity variation of a component as a function of composition. In order to develop the methodology, it is necessary to identify a complete routine to estimate chemical potential values.

The basic requirement for constructing the chemical potential diagram is to estimate the free energy values of all possible phases based upon the equivalent reference states so that the free energy values of intermediate phases can be compared with respect to the same reference state. Then, the stable free energy trajectory is projected on the ternary isothermal phase diagram (the free energy plane is represented by a curved surface in a ternary system). The three chemical potential values at a specified composition (at the point $M\left(X_{A}, X_{B}, X_{C}\right)$, where $X_{A}+X_{B}+X_{C}=1$ and $X_{i}$ is the mole fraction of $i$ ) for a ternary solution may be expressed as equation (1)-(3) [26]:

$$
\begin{gathered}
\mu_{\mathrm{A}}=\mathrm{G}_{\mathrm{m}}-\mathrm{X}_{\mathrm{B}}\left(\partial \mathrm{G}_{\mathrm{m}} / \partial \mathrm{X}_{\mathrm{B}}\right)-\mathrm{X}_{\mathrm{C}}\left(\partial \mathrm{G}_{\mathrm{m}} / \partial \mathrm{X}_{\mathrm{C}}\right) \\
\mu_{\mathrm{B}}=\mathrm{G}_{\mathrm{m}}-\left(1-\mathrm{X}_{\mathrm{B}}\right)\left(\partial \mathrm{G}_{\mathrm{m}} / \partial \mathrm{X}_{\mathrm{B}}\right)-\mathrm{X}_{\mathrm{C}}\left(\partial \mathrm{G}_{\mathrm{m}} / \partial \mathrm{X}_{\mathrm{C}}\right) \\
\mu_{\mathrm{C}}=\mathrm{G}_{\mathrm{m}}-\mathrm{X}_{\mathrm{B}}\left(\partial \mathrm{G}_{\mathrm{m}} / \partial \mathrm{X}_{\mathrm{B}}\right)-\left(1-\mathrm{X}_{\mathrm{C}}\right)\left(\partial \mathrm{G}_{\mathrm{m}} / \partial \mathrm{X}_{\mathrm{C}}\right)
\end{gathered}
$$


where $\mu_{\mathrm{i}}$ : chemical potential of $\mathrm{i}$ component, $\mathrm{G}_{\mathrm{m}}$ : molar Gibbs free energy at a point and $\mathrm{X}_{\mathrm{i}}$ : mole fraction of component $i$.

Graphically, the three intercept points between the designated tangential plane and the vertical axis of each of the three pure elements indicate the chemical potential values at a certain composition (see [26] for further detailed analyses). For systems with a large solubility the chemical potential (activity) values of components with respect to the composition changes are generally obtained based upon the availability of the free energy values. While for many ternary systems the free energy data with respect to large composition changes is lacking, the free energy values of compounds that have a limited solubility are relatively well-determined. Actually, for the systems that have a limited solubility (assumed to be a linear compound), it is only required to have free energy values of those compounds at a given composition, assuming that they are linear compounds, in order to calculate the chemical potential values.

The tangential chemical potential planes of three components in a hypothetical A-B-C ternary system are constructed with respect to a simplified model isothermal ternary diagram in Figure 1, in which only four three-phase equilibrium regions exist; $A-A_{2} B-A_{2} C, A_{2} B-A_{2} C-A_{2}, A_{2}-A_{2} C-C$ and $\mathrm{AB}_{2}$-B-C. Based upon the tangential planes of Figure 1(a) the chemical potential diagram of component $\mathrm{A}$ is constructed in Figure 1(b). It should be noted that the tangential free energy value of a three phase field is expressed as a line, and that of a two phase field is placed between three phase regions (between lines) in Figure $2 b$. For example, for the $A_{2} B-A_{2} C-A_{2}$ three phase equilibrium region, the chemical potential value of component $\mathrm{A}$ may be determined as $\mu_{A}\left(\right.$ at $\left.A_{2} B\right)=\mu_{A}\left(\right.$ at $\left.A B_{2}\right)=R T \ln a_{A}$, where $a_{A}$ : activity of component A . It should be mentioned that the chemical potential value of component $\mathrm{A}$ is determined by the two phase equilibrium of $\mathrm{A}_{2} \mathrm{~B}$ $\mathrm{AB}_{2}$ in this model ternary system. In the similar routine, the chemical potential values of other equilibrium regions can be determined for all of the equilibrium planes as shown in Figure 1(b). Again, if the same graphical method is applied to find chemical potential values, the values of $\mu_{\mathrm{B}}$ and $\mu_{\mathrm{C}}$ can be obtained. The virtue of this analysis is that the chemical potential (and/or activity) of a component on each three phase equilibrium plane can be obtained with a relatively simple calculation by using a graphical method, and thus the chemical potential changes can be identified upon developed intermediate phases (diffusion pathway) during interdiffusion reactions.

\section{Thermodynamic Stability of Ti-Si-Al and SiC/Me Reactions}

Since $\mathrm{Al}$ in the $\mathrm{Ti}-\mathrm{Si}-\mathrm{Al}$ system has a low melting temperature compared to $\mathrm{Ti}$ and $\mathrm{Si}$, previous studies have concentrated on the equilibria in the Ti-rich area. After the partial isothermal sections were reported by Crossley and Turner [27], several studies have been published, including five ternary phases [28-32]. However, since incomplete binary phase diagrams of Ti-Al system and Ti-Si system have been used to identify phase equilibria, the published isothermal sections do not indicate the binary phase equilibria properly. For example, the isothermal sections at $823 \mathrm{~K}$ and 1,473 $\mathrm{K}$ [28] do not include the equilibrium involving the $\mathrm{Ti}_{5} \mathrm{Si}_{4}$ phase, and the isothermal section at $973 \mathrm{~K}$ [29] does not contain $\alpha_{2}-\mathrm{Ti}_{3} \mathrm{Al}$. Recently, during an investigation of the dual phase properties of $\mathrm{Ti}_{5} \mathrm{Si}_{3}$ and titanium aluminides, Wu et al. [33,34] showed the phase equilibria between $\mathrm{Ti}_{5} \mathrm{Si}_{3}$ phase and $\gamma$-TiAl, $\alpha_{2}-\mathrm{Ti}_{3} \mathrm{Al}$ phase at $1,473 \mathrm{~K}$. Although a limited isothermal phase diagram is available, it has been 
recognized that the $\mathrm{Ti}_{5} \mathrm{Si}_{3}$ phase is in equilibrium with several titanium aluminides. Therefore, it is useful to calculate the isothermal phase diagram with complete binary thermodynamic data at above $1,273 \mathrm{~K}$.

Figure 1. Schematic diagram of (a) three-dimensional tangential plane of free energy and (b) two- dimensional chemical potential diagram [6].
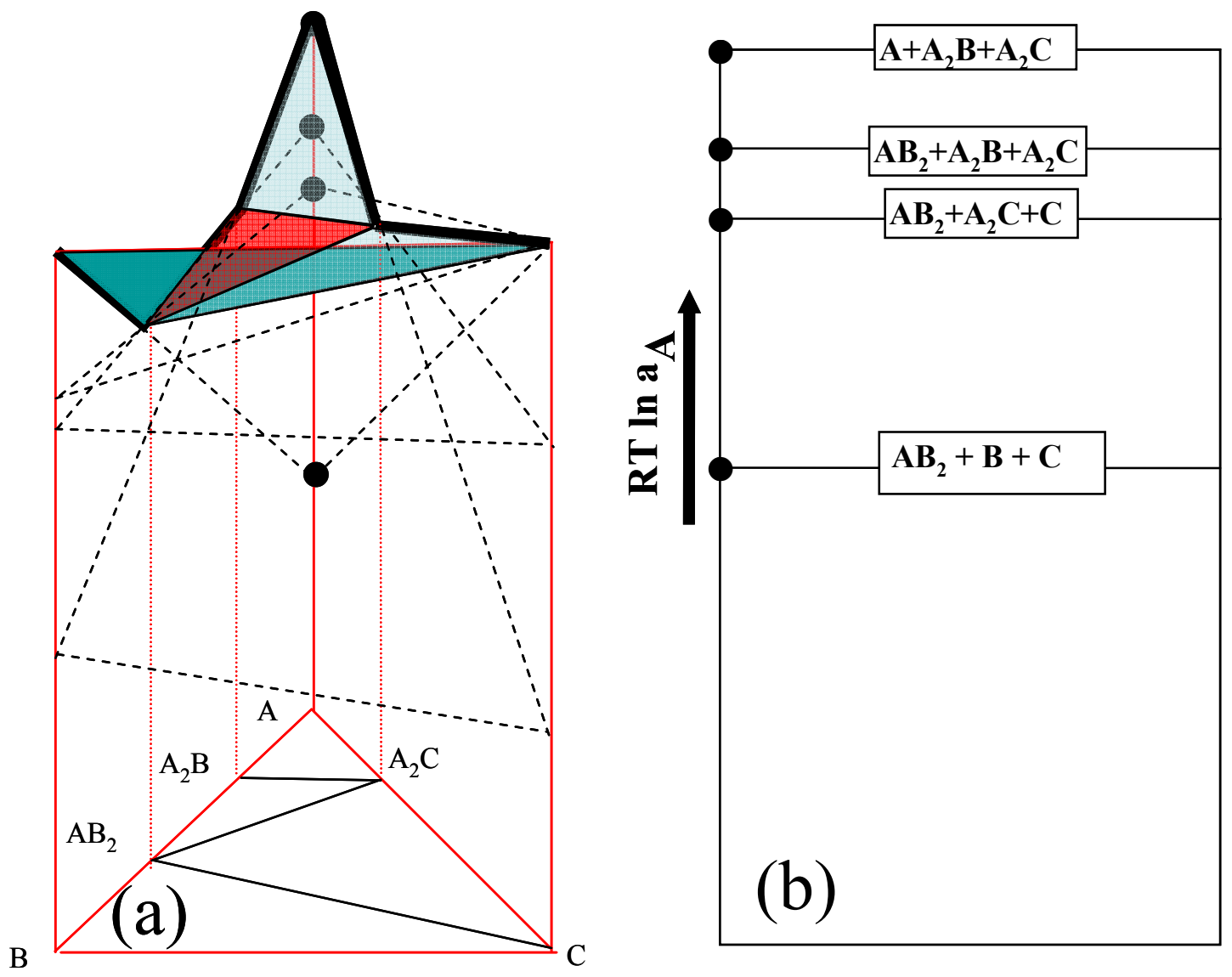

In constructing the isothermal phase diagram, the isothermal section at $1,373 \mathrm{~K}$ has been estimated based upon binary phase information [35-37]. Because the free energy values of ternary phases are not available, only binary phases are considered to determine phase equilibria. In this calculation, the standard states were chosen as bcc-Ti, diamond cubic-Si and liquid Al, respectively. The estimated free energy values are shown in Table 1 . Since the free energy values of $\mathrm{Ti}_{3} \mathrm{Al}, \mathrm{TiAl}$ and $\mathrm{TiAl}_{3}$ are described by a superlattice model, the values of the site fraction of atoms in the superlattice indicating minimum free energy values at the given composition were chosen for estimation [37]. Then, the minimum free energy values were determined by adjusting reference reactions. Finally, the various two phase equilibria have been determined by considering the competition of the possible reactions without alloy phase solubility. Based upon this calculation, the isothermal section was determined at 1,373 $\mathrm{K}$ as shown in Figure 2. The results of the determination of the isothermal section indicate that the $\mathrm{TiSi}_{2}$ phase is not in equilibria with titanium aluminides. However, the $\mathrm{Ti}_{5} \mathrm{Si}_{3}$ phase is in equilibrium with titanium aluminides and thus would provide for a stable reinforcement phase upon formation by an in situ reaction, leading that the investigation of the $\mathrm{TiSi}_{2} / \mathrm{TiAl}$ reaction couples is useful for monitoring the formation of $\mathrm{Ti}_{5} \mathrm{Si}_{3}$ in the $\mathrm{TiAl}$ phase. 
Figure 2. Calculated isothermal phase diagram of the Ti-Si-Al system at 1,373 K [7].

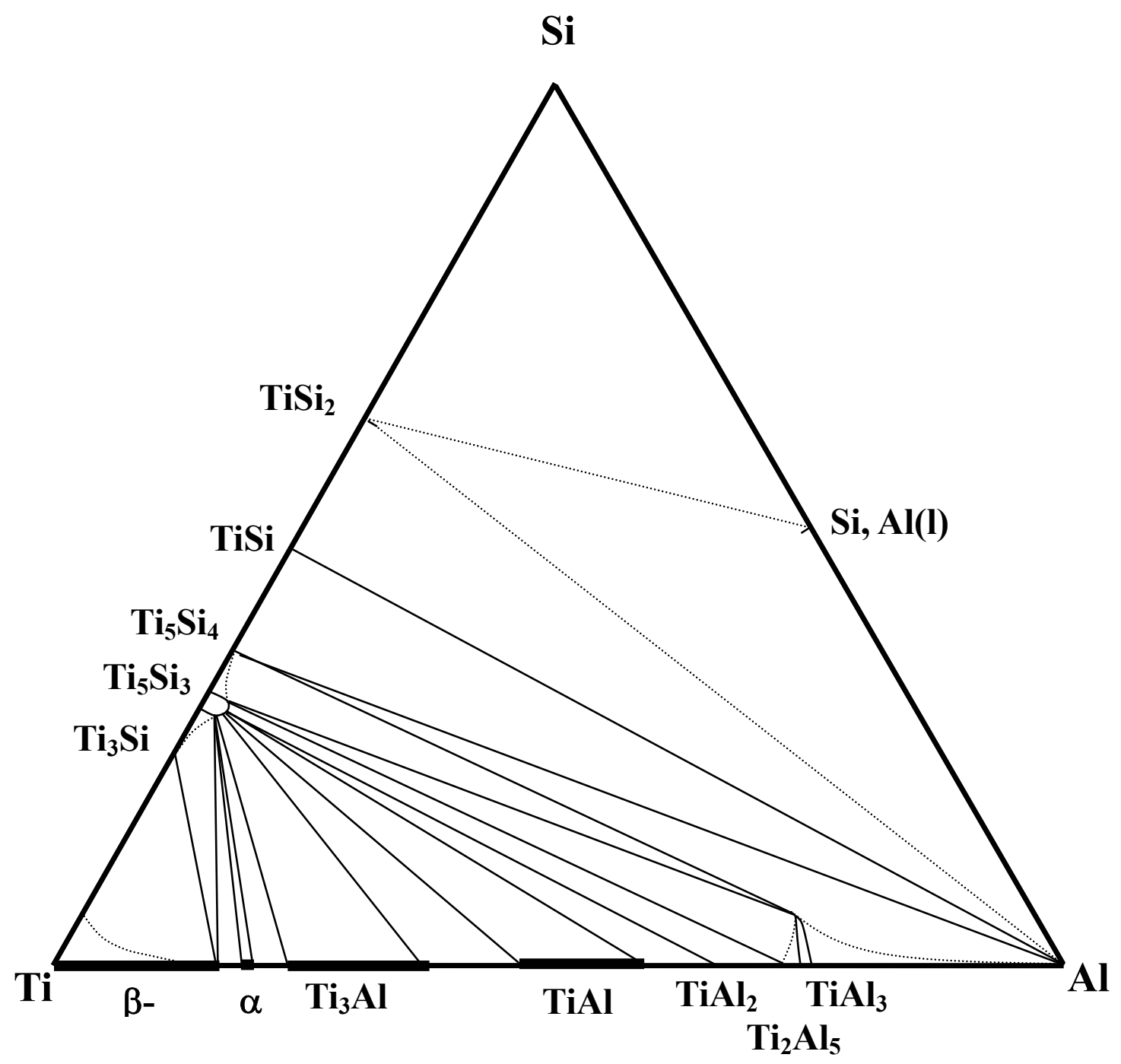

On the other hand, for the $\mathrm{SiC} / \mathrm{Me}$ reactions, the properties of the contact materials affect the final diffusion pathway and morphology. The interface reactions of $\mathrm{SiC} / \mathrm{Metal}$ have been reported and include investigations on the thermal compatibility and/or the solid state reactions [38]. The reaction product sequence and interface morphology in $\mathrm{SiC} /$ Metal reactions are mainly dependent on the contact materials. For example, the products of the $\mathrm{SiC} / \mathrm{Ni}$ reaction show a periodic morphology composed of alternating carbon and silicides [39], but those of the $\mathrm{SiC} / \mathrm{Cr}$ reaction reveal planar layers of carbides and silicides [21]. While the characterization of individual SiC/Metal interface reactions provides useful information, this is not sufficient to interpret the mechanism governing the SiC/Metal reactions and reaction modes. Some reviews about $\mathrm{SiC} /$ Metal reactions regarding to the phase equilibria and phase evolution have been published [40-42]. However, it is still necessary to define governing factors and reaction pathways. In fact, the compiled data basis for the SiC/Metal interface reactions can offer a guideline to control the interface properties and phase evolution as well. For example, when the reaction products obtained during interdiffusion processing are not favorable in terms of material properties, a modification of the diffusion pathway can be designed by employing a constructed database to identify a suitable phase combination selection. In the case of the formation of 
free carbon during $\mathrm{SiC} / \mathrm{X}(\mathrm{I})$ reaction such as the $\mathrm{SiC} / \mathrm{Ni}$ combination, the reaction pathway should involve the formation of silicides in order to satisfy the mass balance.

If the contact material is a strong carbide former such as Mo (affinity of C and metal is high) [43], free carbon is not obtained as a product but rather carbides and silicides. It should be noted that in the diffusion zone the neighboring phase of a carbide or ternary phase is always a silicide. Therefore, it appears that two governing factors - the phase equilibria and mass balance requirements - affect the formation of the product sequence. It has been previously documented that the reaction mode representing the $\mathrm{SiC} / \mathrm{Me}$ systems has been reported as three different types [42]:

$$
\begin{aligned}
& \mathrm{Me}+\mathrm{SiC}=\text { Silicide }+\mathrm{C}(\text { graphite }) \\
& \mathrm{Me}+\mathrm{SiC}=\mathrm{Silicide}+\text { Carbide } \\
& \mathrm{Me}+\mathrm{SiC}=\mathrm{Si}+\text { Carbide }
\end{aligned}
$$

However, with closer examination, since the formation of products in the $\mathrm{SiC} / \mathrm{Me}$ reaction is governed by a local equilibrium, the formation of $\mathrm{Si}$ in the above reactions Type III is not probable based upon the isothermal phase diagram. The recent experimental results about the SiC/Mo and $\mathrm{SiC} / \mathrm{V}$ reactions which were claimed as type III can be re-examined by the virtue of the current consideration. The diffusion pathways of the $\mathrm{SiC} / \mathrm{Mo}$ and $\mathrm{SiC} / \mathrm{V}$ reactions have been reported as follows:

$$
\begin{gathered}
\mathrm{SiC} / \mathrm{Mo} \rightarrow \mathrm{SiC} / \mathrm{Mo}_{5} \mathrm{So}_{3} \mathrm{C} / \mathrm{Mo}_{5} \mathrm{Si}_{3} / \mathrm{Mo}_{3} \mathrm{C} / \mathrm{Mo} \text { [44] } \\
\mathrm{SiC} / \mathrm{V} \rightarrow \mathrm{SiC} / \mathrm{VC} / \mathrm{V}_{5} \mathrm{Si}_{3} / \mathrm{V}_{2} \mathrm{C} / \mathrm{V}[45]
\end{gathered}
$$

Based upon the above considerations, it is clear that a type II reaction is equivalent to the type III reaction in terms of the formation of carbides and silicides. The resultant reaction modes representing the $\mathrm{SiC} / \mathrm{Me}$ systems have been formulated as follows:

$$
\begin{aligned}
& \mathrm{Me}+\mathrm{SiC} \rightarrow \text { Silicides }+\mathrm{C}(\text { graphite }) \\
& \mathrm{Me}+\mathrm{SiC} \rightarrow \text { Silicides }+ \text { Carbides }+\left(\mathrm{Me}_{\mathrm{x}} \mathrm{Si}_{\mathrm{y}} \mathrm{C}_{\mathrm{z}}\right)
\end{aligned}
$$

The silicides with free carbon mixtures are products of $\mathrm{SiC} / \mathrm{X}(\mathrm{I})$ reactions, and the silicides with carbide layers are the products of $\mathrm{SiC} / \mathrm{X}$ (II) reactions. A ternary phase $\left(\mathrm{Me}_{\mathrm{x}} \mathrm{Si}_{\mathrm{y}} \mathrm{C}_{\mathrm{z}}\right)$ is included in parenthesis to generalize the reaction path to include ternary systems with no reported ternary phase such as the Si-C-V system.

Based upon published isothermal phase diagrams of ternary Si-C-X (X : Ni[46], Ti [47], Mo [48], etc.) systems, two general points can be made concerning these systems. First, the solubility of silicides and carbides is limited. In the case of the Si-C-Ni ternary system $\left(850^{\circ} \mathrm{C}\right)$, a limited solubility of silicides and carbide ( $\mathrm{SiC}$ ) has been reported [49]. Second, if a ternary phase exists, it is in equilibrium with one of the carbides and silicides. For example, in the Si-C-Mo system $\left(1,200{ }^{\circ} \mathrm{C}\right)$, the ternary phase $\left(\mathrm{Mo}_{5} \mathrm{Si}_{3} \mathrm{C}\right)$ is in equilibrium with the $\mathrm{Mo}_{2} \mathrm{C}$ and $\mathrm{Mo}_{5} \mathrm{Si}_{3}$ phases [19]. From this comparison, the Si-C-X ternary systems can be separated into type I and type II based upon the shape of the isothermal phase diagram. The main features of type I and type II are the following:

Type I: (1) There is no compound in the Me-C binary system.

(2) A three phase region (SiC-C-Silicide) exists in the ternary isothermal phase diagram. 
Type II: (1) At least one compound exists in the Me-C binary system.

(2) If a ternary phase exists, it is in equilibrium with a silicide and a carbide (no ternary phase is reported in the Si-C-W [50] and Si-C-V [51] systems).

In order to simplify the description of the $\mathrm{Si}-\mathrm{C}-\mathrm{X}$ systems, two schematic ternary isothermal phase diagrams of Si-C-X systems with the diffusion pathway and reaction modes are illustrated in Figures 3 and 4, respectively. The temperature of these diagrams is assumed to be under the melting temperature of any binary or ternary phase. Since the reaction pathway is affected by the phase equilibria, it is meaningful to examine the diffusion pathway based upon this information.

Figure 3. Schematic figure showing the sequence of the products with respect to the contact materials [7].

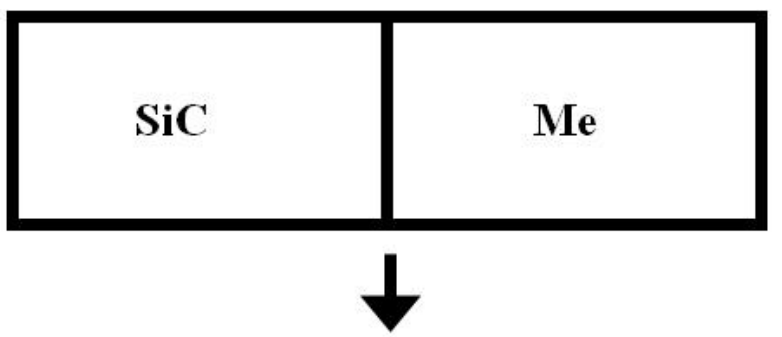

\section{Phase sequence affected by the contact materials}

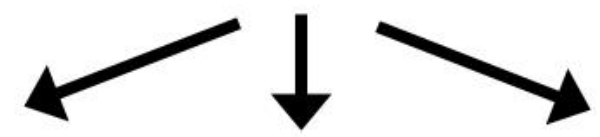

Free Carbon

Carbide

Ternary phase

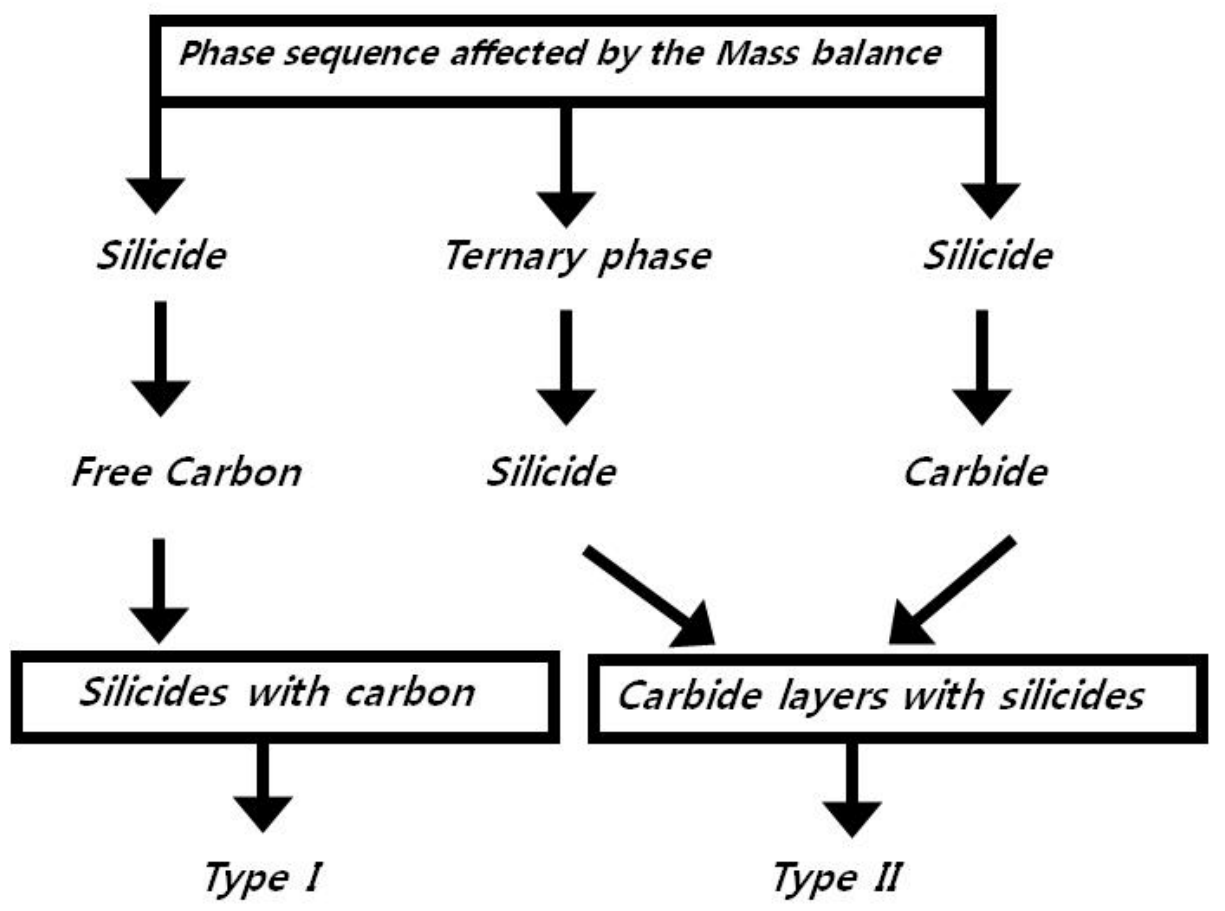


Figure 4. The schematic isothermal phase diagrams and reaction pathway of $\mathrm{SiC} / \mathrm{X}(\mathrm{I})$ and $\mathrm{X}(\mathrm{II})$ [6].

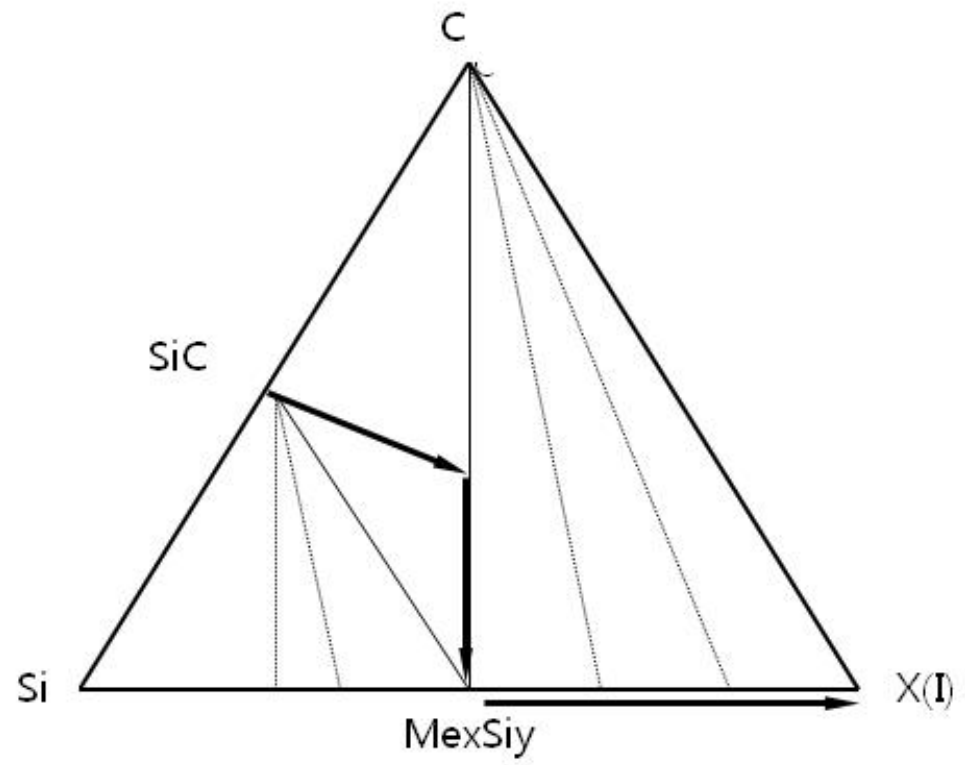

$\mathrm{X}(\mathrm{I})$ : $\quad \mathrm{Ni}, \mathrm{Pd}, \mathrm{Pt}$ (Periodic structure)

$\mathrm{Fe}, \mathrm{Co}$ (mixture of $\mathrm{C}$ and silicides)

pathway : SiC / C + Silicide / C + Silicide /... X(I)

pathway: $\mathrm{SiC} / \mathrm{C}+$ Silicides $/ \mathrm{X}$ (II)

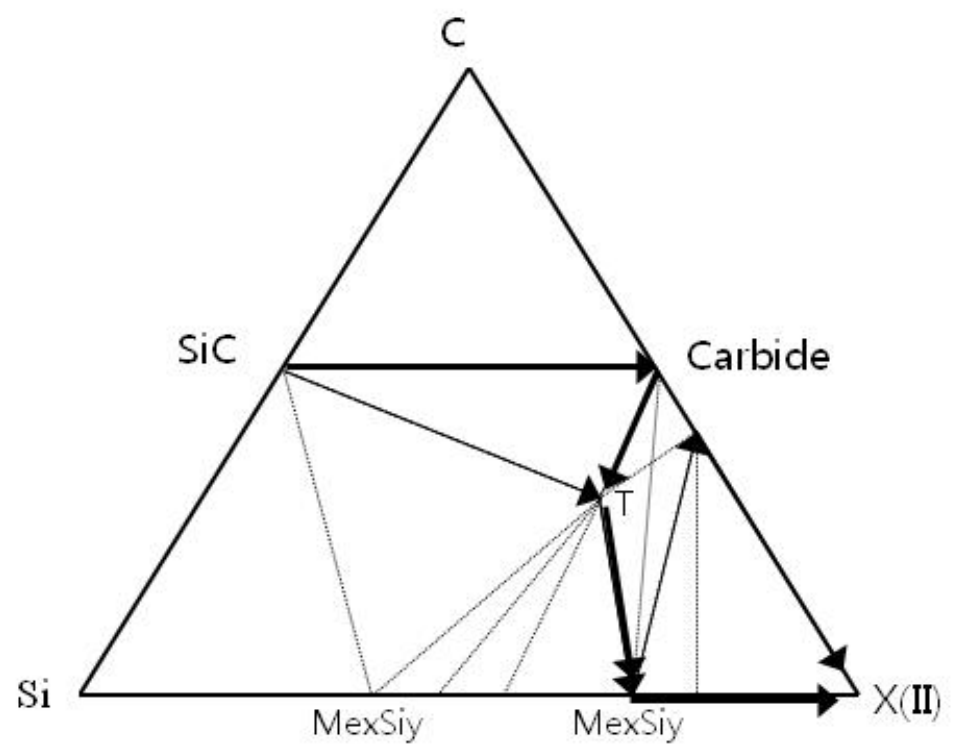

$\mathrm{X}$ (II) : Mo, $\mathrm{Cr}, \mathrm{Ti} \longrightarrow$
$\mathrm{Nb}$
pathway : SiC / T phase / Silicides / Carbide / X(I)
pathway : SiC / Carbide / T phase / Silicides / (Carbide) / X(II)




\section{Diffusion Pathway in the $\mathrm{SiC} / \mathrm{Ni}$ and $\mathrm{SiC} / \mathrm{Cr}$ Systems}

$\mathrm{SiC} / \mathrm{Ni}$ (type I) and $\mathrm{SiC} / \mathrm{Cr}$ (type II) interface reactions have been examined in detail to identify the entire diffusion pathway. Since both reactions have been well documented in previous works [20,21], efforts have been concentrated on defining the main distinguishing points. It has been reported that the formation of a periodic morphology is due to the difference of individual element mobility. For the $\mathrm{SiC} / \mathrm{Ni}$ system, $\mathrm{Ni}$ is the main moving component, while carbon is immobile [20]. Since the knowledge of the kinetic behavior of components during periodic phase formation is important for understanding the reaction kinetics, SiC/Ni (type I) reaction couples were prepared and investigated.

\subsection{SiC/Ni Reactions}

The BSE image of a $\mathrm{SiC} / \mathrm{Ni}$ reaction couple annealed at $900{ }^{\circ} \mathrm{C}$ for $40 \mathrm{~h}$ is shown in Figure 5 . Periodic layers of silicides and carbon were developed as products. The observed product sequence by EPMA is as follows:

$$
\mathrm{SiC} / \mathrm{Ni} \rightarrow \mathrm{Ni} / \mathrm{Ni}_{3} \mathrm{Si} / \mathrm{Ni}_{5} \mathrm{Si}_{2}+\mathrm{C} / \mathrm{Ni}_{5} \mathrm{Si}_{2} / \mathrm{Ni}_{5} \mathrm{Si}_{2}+\mathrm{C} . / \mathrm{Ni}_{2} \mathrm{Si}+\mathrm{C} . . / \mathrm{SiC} .
$$

Figure 5. Back Scattered Electron image of $\mathrm{Ni} / \mathrm{SiC}$ reaction couple annealed at $900{ }^{\circ} \mathrm{C}$ for $40 \mathrm{~h}[6]$.

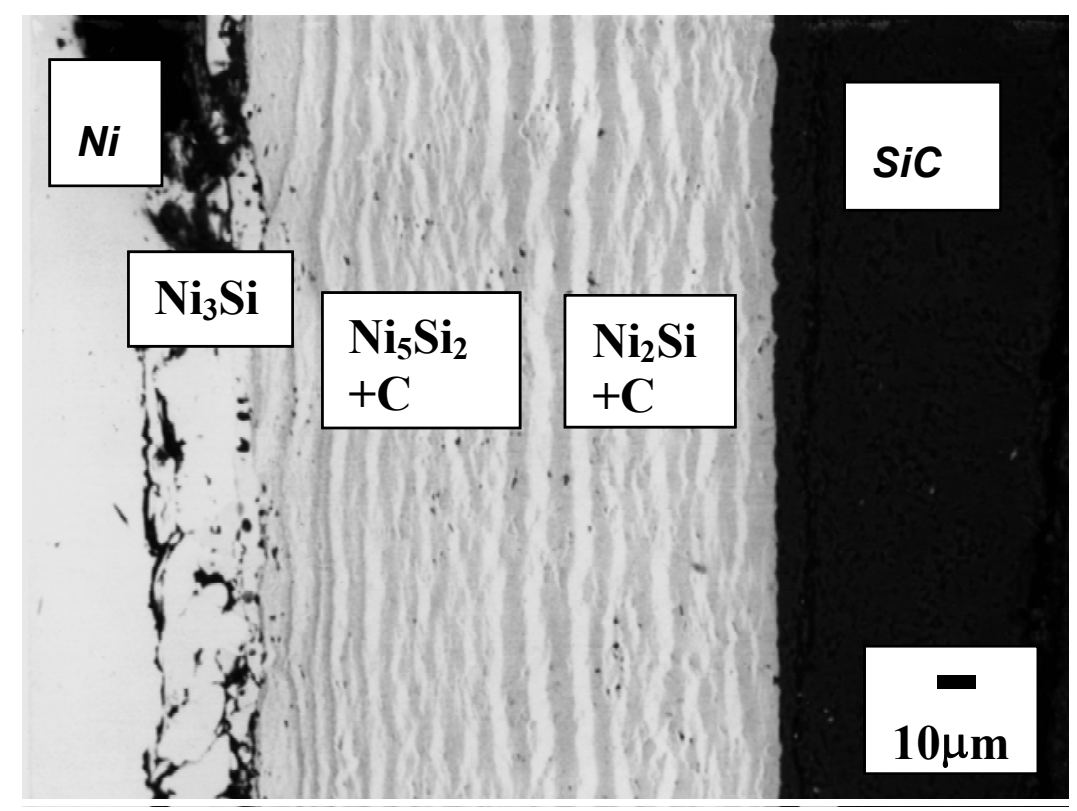

After diffusion annealing of $\mathrm{SiC} / \mathrm{Ni}$ reaction couples with markers, van Loo and coworkers [20] reported that the placement of marker has been found at the interface of $\mathrm{Ni}$ (one of the end material) and silicides and no traces of carbon or silicon were found on the Ni side. In other words, the Kirkendall marker moved towards the Ni side. If Si or C diffuses over the Ni side, the trace of Si or C should be observed on the Ni side of the Kirkendall marker. Therefore, it can be concluded that the Ni is virtually the only moving component in the $\mathrm{SiC} / \mathrm{Ni}$ reaction. During the $\mathrm{SiC} / \mathrm{Ni}$ reaction, Ni diffuses into $\mathrm{SiC}$, and $\mathrm{SiC}$ is decomposed into $\mathrm{Si}$ and $\mathrm{C}$, and the decomposed $\mathrm{Si}$ reacts with $\mathrm{Ni}$ to form silicides and free carbon [20]. The presence of the products (silicides and carbon) found at both Ni and SiC side 
can be understood based upon the vacancy flow. After Ni diffuses toward SiC side, the opposite net flux of the vacancy flow would increase the vacancies of $\mathrm{Ni}$ side resulting in the lattice movement toward the Ni side. At the same time, the volume changes will be involved during reactive diffusion. Assuming that $\mathrm{Ni}$ and $\mathrm{SiC}$ would form the silicides and carbon, the reaction can be made as follows:

$$
10 \mathrm{Ni}+4 \mathrm{SiC} \rightarrow \mathrm{Ni}_{3} \mathrm{Si}+\mathrm{Ni}_{5} \mathrm{Si}_{2}+\mathrm{Ni}_{2} \mathrm{Si}+\mathrm{C}
$$

Considering the molar volumes of the phases (see Table 1), the volume change for the above reaction is estimated as a $54.9 \%$ reduction based upon the initial volume. The large amount of the volume change for the reaction indicates that a stress can develop and should be considered for the $\mathrm{SiC} / \mathrm{Ni}$ interface reaction. For the development of the periodic layers, two models have been proposed [28]. First, the band, which is formed at the substrate, reaches a critical thickness. Then, the band is lifted from the substrate due to the mechanical stresses accompanying the growth of the band. Then, a new surface (without bands) starts to react and the reaction proceeds during the interdiffusion. The estimated large amount of volume change supports this model. The second model involves the large difference of the component diffusivities. When the first band is formed, one component diffuses fast through the produced band during the interdiffusion. This would produce the product phase (silicide) behind the produced band (carbon + silicides) so that a periodic band morphology develops at the interface. As aforementioned, the Kirkendall markers have been observed at the interface between pure $\mathrm{Ni}$ and silicides implying that $\mathrm{Ni}$ is virtually the only moving component. This experimental result supports the second model. Therefore, it is considered that both two reaction models operate concurrently to produce the periodic layer morphology.

Table 1. The crystallographic data and molar volumes of Si-C-Ni system [6].

\begin{tabular}{|c|c|c|c|c|}
\hline Phase & Pear. Sym. & Prototype & $\mathbf{Z}$ & Mol. Vol. \\
\hline $\mathrm{C}$ & $\mathrm{hP} 4$ & Graphite & 4 & 5.31 \\
\hline$\beta-\mathrm{SiC}$ & $\mathrm{cF} 8$ & $\mathrm{ZnC}$ & 8 & 6.23 \\
\hline $\mathrm{Ni}$ & $\mathrm{cF} 4$ & $\mathrm{Al}, \mathrm{Cu}$ & 4 & 6.58 \\
\hline$\beta-\mathrm{Ni}_{3} \mathrm{Si}$ & $\mathrm{cP} 4$ & $\mathrm{~L} 1_{2}$ & 4 & 6.48 \\
\hline $\mathrm{Ni}_{5} \mathrm{Si}_{2}$ & $\mathrm{hP43}$ & $\mathrm{Ni}_{31} \mathrm{Si}_{12}$ & 43 & 6.63 \\
\hline$\delta-\mathrm{Ni}_{2} \mathrm{Si}$ & $\mathrm{oP} 12$ & $\mathrm{Co}_{2} \mathrm{Si}$ & 12 & 6.59 \\
\hline$\theta-\mathrm{Ni}_{2} \mathrm{Si}$ & $\mathrm{hP} 6$ & $\mathrm{Ni}_{2} \mathrm{In}$ & 6 & 6.33 \\
\hline $\mathrm{NiSi}$ & $\mathrm{oP} 8$ & $\mathrm{MnP}$ & 8 & 7.32 \\
\hline $\mathrm{NiSi}$ & $\mathrm{cF} 12$ & $\mathrm{CaF}$ & 12 & 7.93 \\
\hline $\mathrm{Si}$ & $\mathrm{cF} 4$ & $\mathrm{C}(\mathrm{Dia})$. & 8 & 12 \\
\hline
\end{tabular}




\section{2. $\mathrm{SiC} / \mathrm{Cr}$ Reactions}

The product phase sequence of $\mathrm{SiC} / \mathrm{Cr}$ in the temperature range between $1,000{ }^{\circ} \mathrm{C}$ and $1,200{ }^{\circ} \mathrm{C}$ has been reported as follows [17]:

$$
\mathrm{SiC} / \mathrm{Cr} \rightarrow \mathrm{SiC} / \mathrm{Cr}_{5} \mathrm{Si}_{3} \mathrm{C} / \mathrm{Cr}_{7} \mathrm{C}_{3}+\mathrm{Cr}_{3} \mathrm{Si} / \mathrm{Cr}_{7} \mathrm{C}_{3} / \mathrm{Cr}_{23} \mathrm{C}_{6} / \mathrm{Cr}
$$

It should be noted that the carbide layers are produced next to the $\mathrm{Cr}$ side, indicating that the diffusion distance of carbon from the $\mathrm{SiC}$ is larger than that of $\mathrm{Si}$ in $\mathrm{SiC}$.

\section{Diffusion Pathway Analysis and Chemical Potential Diagram}

The various composite design features emphasize the importance of the diffusion path that is followed during reaction in multicomponent systems. The prediction of the diffusion path from theory requires detailed knowledge of the diffusivities for each component, including cross terms, as well as a complete phase diagram including two phase field tie lines. For a ternary system this means that information on diffusivities is available for each phase. Even though there are constraints on the diffusivities that can be applied to reduce the data base requirements, the necessary information for theoretical prediction is still large and generally unavailable for given multicomponent systems. In order to provide some theoretical guidance to judge the diffusion path trajectory, alternative approaches have been proposed based upon simplified conditions [52,53]. All analysis methods include two basic requirements of diffusion path. First, the pathway should cross the line connecting the end member compositions in order to satisfy mass balance. Secondly, a stable path should follow the isothermal phase diagram, and coincide with two-phase field tie lines to satisfy local equilibrium. Accordingly, the accumulated knowledge on the diffusion pathway can provide a strategy for materials selection during phase evolution.

Since the formation of product phases is affected by the chemical potential, it is useful to consider the observed diffusion pathway within the chemical potential framework [26]. While the chemical potential diagrams of the $\mathrm{SiC} / \mathrm{Cr}$ reaction are accessible [21], it is useful to examine the $\mathrm{SiC} / \mathrm{Ni}$ reaction. Chemical potential diagrams with respect to $\mathrm{Si}, \mathrm{C}$ and $\mathrm{Ni}$ have been constructed based upon the free energy values of each phase, assuming that each phase is a line compound (i.e., the solubility of each phase is negligible). From the estimated values of binary systems the chemical potential values in the ternary system has been estimated with a graphical method. The resulting activity values of ternary regions are shown in Table 2 . The schematic three dimensional diagram based upon these values is illustrated in Figure 6. Each plane is the tangential plane at the associated free energy surface. It should be noted that each three phase equilibrium plane of the isothermal phase diagram corresponds to each tangential plane. The extension of the tangential plane to the three axes indicates the chemical potential values. For example, the extension of the $\mathrm{Ni}_{3} \mathrm{Si}+\mathrm{Ni}_{5} \mathrm{Si}_{2}+\mathrm{C}$ plane to the axes indicates the chemical potential values of $\mathrm{Ni}, \mathrm{Si}$ and $\mathrm{C}$ (Figure 7). Based upon this three-dimentional diagram, the chemical potential diagrams with respect to Ni (Figure 7a), Si (Figure 7b) and C (Figure 7c) have been constructed at $900{ }^{\circ} \mathrm{C}$. Also, the diffusion pathway of $\mathrm{SiC} / \mathrm{Ni}$ is marked in the stability diagrams. While the chemical potentials of $\mathrm{Si}$ and $\mathrm{Ni}$ decrease, that of carbon increases and decreases through the reaction layers by forming free carbon. For the $\mathrm{SiC} / \mathrm{Cr}$ reaction, it has been reported that the chemical 
potentials of $\mathrm{Si}, \mathrm{C}$ and $\mathrm{Cr}$ decrease through the reaction layer (see [20] for component chemical potential diagrams). Since for type I reactions, the chemical potential of carbon increases and decreases through the reaction zone due to the production of free carbon from SiC, the identification of the chemical potential variation is also a characteristic feature. Therefore, the chemical potential behavior appears to be related to the kinetic difference of reaction modes between the Ni (type I) and the Cr (type II).

Table 2. The estimated activity values of each component in a designated ternary equilibrium plane at $900{ }^{\circ} \mathrm{C}[6]$.

\begin{tabular}{|c|c|c|c|}
\hline \multirow[t]{2}{*}{ Equilibrium Planes } & \multicolumn{3}{|c|}{ Activity values of components } \\
\hline & $\mathbf{N i}$ & $\mathbf{S i}$ & $\mathbf{C}$ \\
\hline $\mathrm{Ni}+\mathrm{Ni}_{3} \mathrm{Si}+\mathrm{C}$ & 1.00 & $7.56 \mathrm{E}-07$ & 1.00 \\
\hline $\mathrm{Ni}_{3} \mathrm{Si}+\mathrm{Ni}_{5} \mathrm{Si}_{2}+\mathrm{C}$ & $4.72 \mathrm{E}-01$ & $7.17 \mathrm{E}-06$ & 1.00 \\
\hline $\mathrm{Ni}_{5} \mathrm{Si}_{2}+\delta-\mathrm{Ni}_{2} \mathrm{Si}+\mathrm{C}$ & $1.20 \mathrm{E}-01$ & $2.22 \mathrm{E}-04$ & 1.00 \\
\hline$\delta-\mathrm{Ni}_{2} \mathrm{Si}+\mathrm{SiC}+\mathrm{C}$ & $3.92 \mathrm{E}-02$ & $2.14 \mathrm{E}-03$ & 1.00 \\
\hline$\delta-\mathrm{Ni}_{2} \mathrm{Si}+\theta-\mathrm{Ni}_{2} \mathrm{Si}+\mathrm{SiC}$ & $8.33 \mathrm{E}-03$ & $4.97 \mathrm{E}-02$ & $4.31 \mathrm{E}-02$ \\
\hline$\theta-\mathbf{N i}_{2} \mathbf{S i}+\mathbf{N i S i}+\mathbf{S i C}$ & $3.39 \mathrm{E}-03$ & $2.46 \mathrm{E}-01$ & $8.70 \mathrm{E}-03$ \\
\hline $\mathbf{N i S i}+\mathbf{N i S i}_{2}+\mathbf{S i C}$ & $2.68 \mathrm{E}-03$ & $3.11 \mathrm{E}-01$ & $6.88 \mathrm{E}-03$ \\
\hline $\mathrm{NiSi}_{2}+\mathrm{SiC}+\mathrm{Si}$ & $2.77 \mathrm{E}-04$ & 1.00 & $2.14 \mathrm{E}-03$ \\
\hline
\end{tabular}

Figure 6. Schematic 3-dimensinal chemical potential diagram of the Si-Ni-C ternary system at $900^{\circ} \mathrm{C}[6]$.

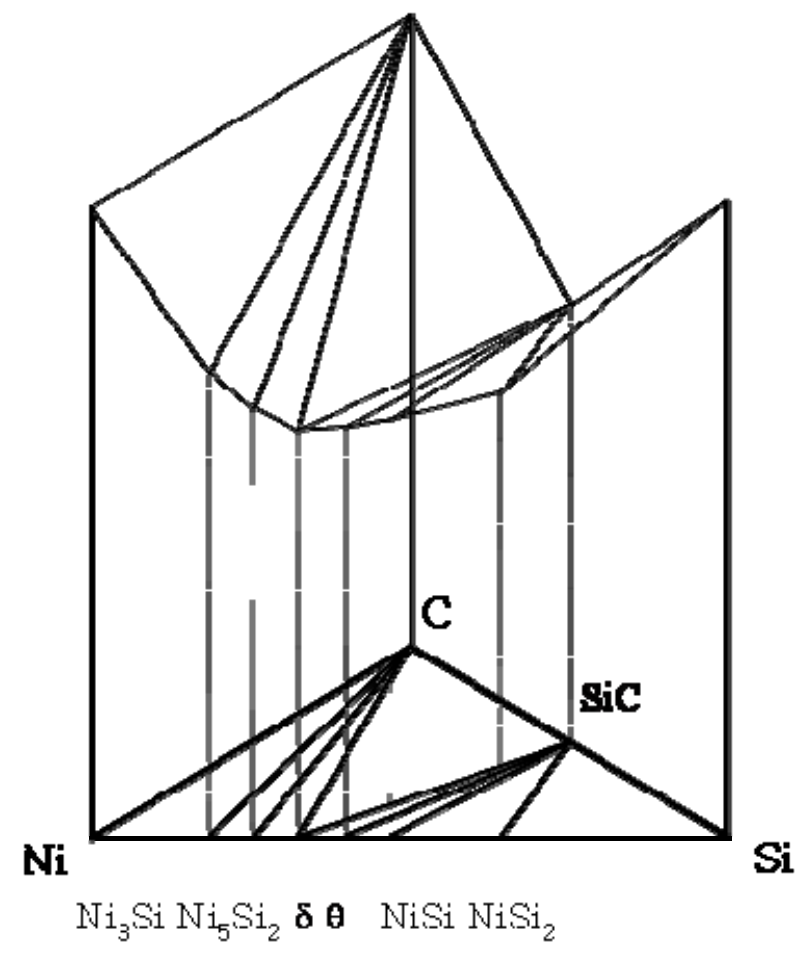


Figure 7. The chemical potential diagrams with diffusion pathway of the Si-C-Ni system (a) with respect to carbon, (b) with respect to nickel, (c) with respect to silicon [6].

(a)

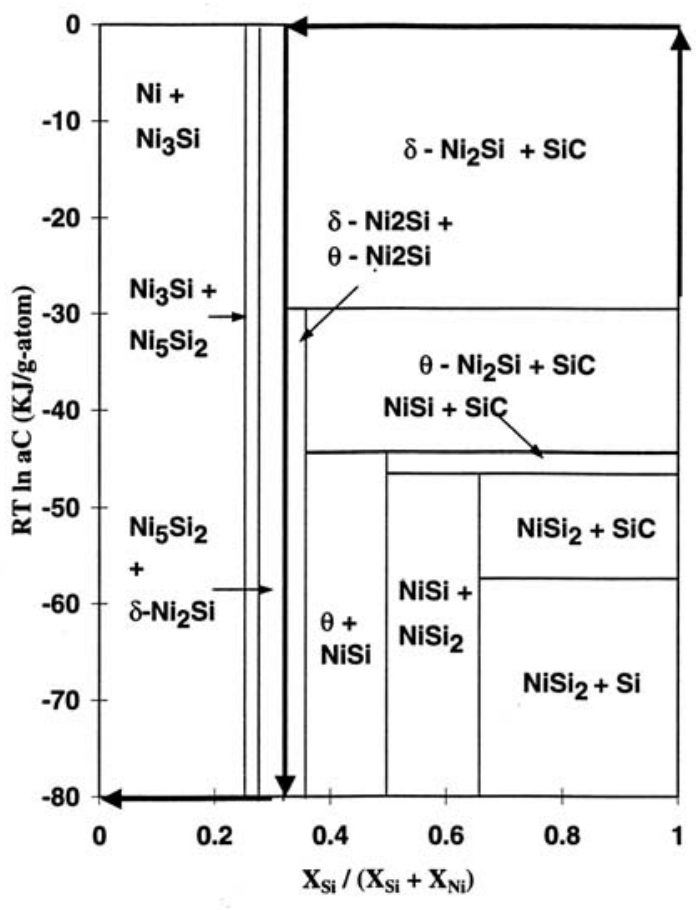

(b)

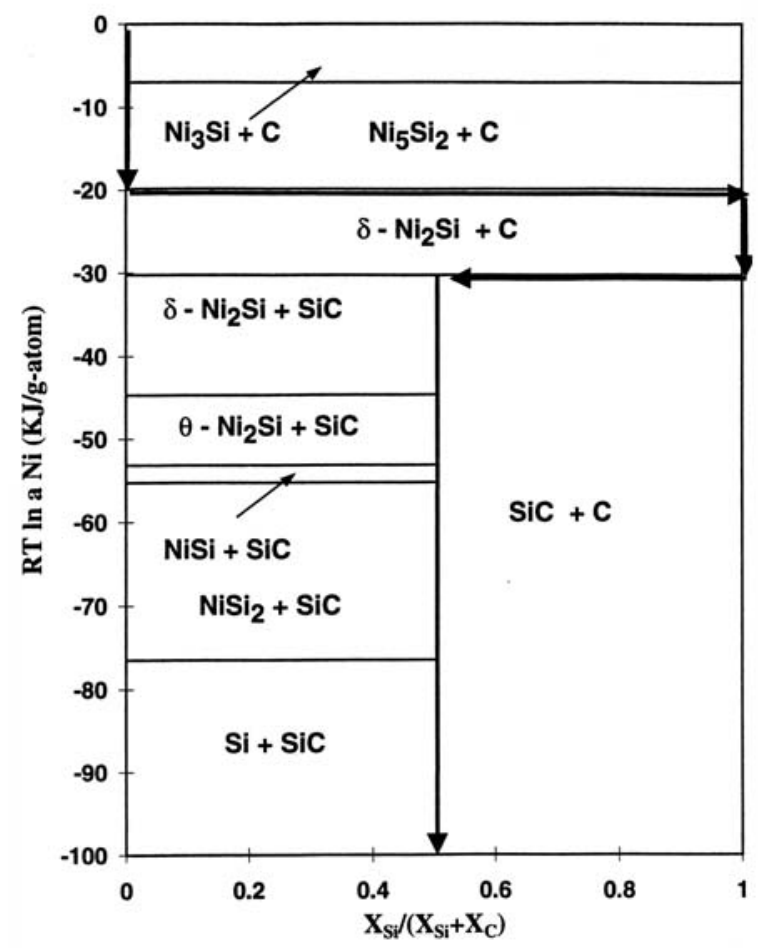

(c)

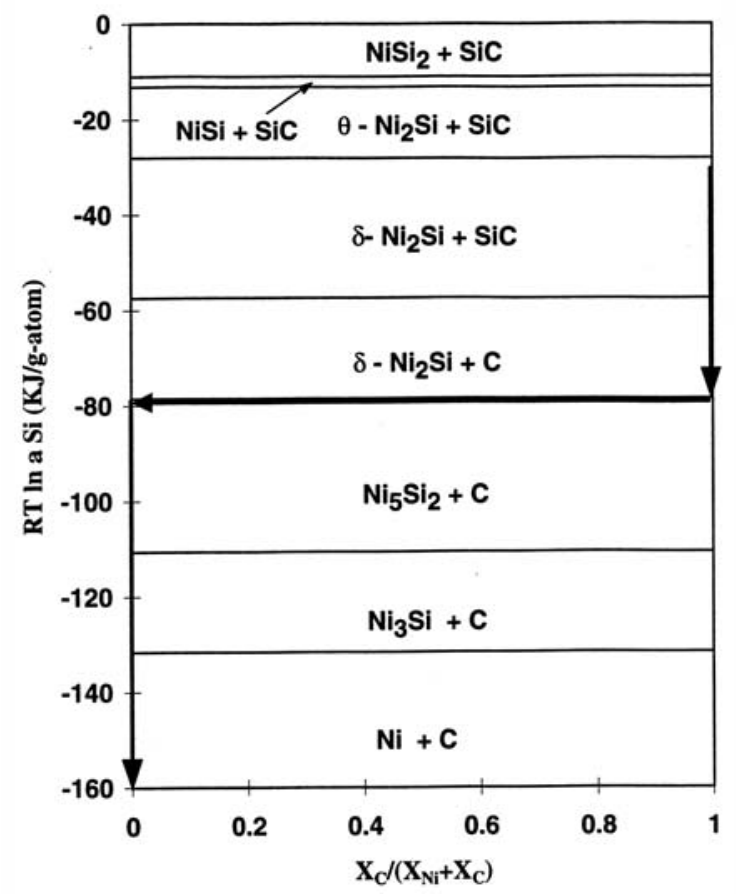


When the reaction extent can be controlled, a thin interface debonding layer can have a beneficial effect on the overall fracture toughness of a composite [54]. The debonding mechanism has been reported that a produced carbon layer can provide a crack deflection site due to the weak strength of carbon at the interface [54]. However, it has also been reported that the reaction kinetics of $\mathrm{SiC} / \mathrm{Ni}$ is fast during isothermal annealing at (and above) $1,000{ }^{\circ} \mathrm{C}$, resulting in a severe degradation of $\mathrm{SiC}$ [55]. This indicates that the control of the periodic layer is placed in the central issue for controlling overall materials properties. In order to examine the effect of a biasing layer (excess flux), a selected biasing interlayer was inserted into a $\mathrm{SiC} / \mathrm{Ni}$ diffusion couple subsequently annealed at $900{ }^{\circ} \mathrm{C}$ for $40 \mathrm{~h} . \mathrm{Cu}$ $(\mathrm{X}(\mathrm{I}))$ and $\mathrm{Cr}(\mathrm{X}(\mathrm{II}))$ have been selected as interlayers based upon the proposed reaction classification. Since the SiC/Ni reaction represents a type I reaction, the application of a type II component such as $\mathrm{Cr}$ would change the carbon flux by producing carbides based upon the above discussion. Indeed, when a $\mathrm{Cu}$ interlayer $(25 \mu \mathrm{m})$ is inserted in a $\mathrm{SiC} / \mathrm{Ni}$ reaction couple, the products are obtained with a periodic layer morphology (Figure 8).

Figure 8. BSE image of $\mathrm{Ni} / \mathrm{Cu} / \mathrm{SiC}$ reaction couple annealed at $900{ }^{\circ} \mathrm{C}$ for $40 \mathrm{~h}$ [6].

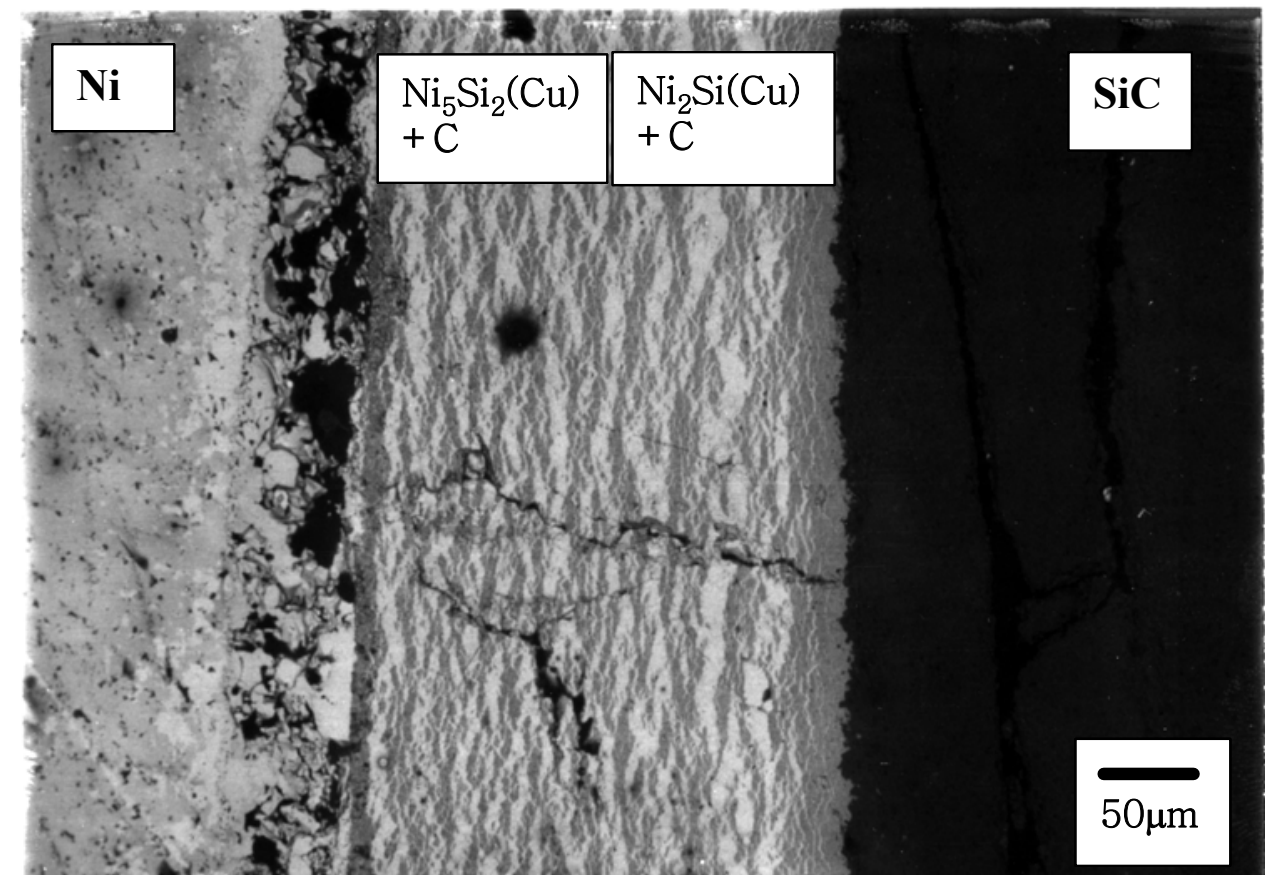

The reaction product sequence was observed as: $\mathrm{Ni} / \mathrm{Ni}{ }_{2} \mathrm{Si}(\mathrm{Cu})+\mathrm{C} / \mathrm{Ni}_{5} \mathrm{Si}_{2}(\mathrm{Cu})+\mathrm{C} / \mathrm{Ni}$. It should be noted that the diffusion of $\mathrm{Cu}$ (interlayer) into both sides is fast, so that the diffusion pathway is moved into the $\mathrm{Ni}$ rich side. However, when a $\mathrm{Cr}$ interlayer ( $\mathrm{Cr}$ was sputter-deposited with a nominal thickness of $10 \mu \mathrm{m}$ ) is placed in a $\mathrm{SiC} / \mathrm{Ni}$ reaction couple, the morphology of the reaction product layers is planar [Figure 9 (a)]. The product sequence identified by EPMA is $\mathrm{Ni}(\mathrm{s} . \mathrm{s}) / \mathrm{Cr} / \mathrm{Cr}_{23} \mathrm{C}_{6} / \mathrm{Cr}_{7} \mathrm{C}_{3} / \mathrm{T}\left(\mathrm{Cr}_{5} \mathrm{Si}_{3} \mathrm{C}\right) / \mathrm{SiC}$. The diffusion of $\mathrm{Cr}$ is relatively stable compared to the $\mathrm{Cu}$ layer and the reaction products are distinctly biased by the excess flux of $\mathrm{Cr}$. In order to investigate the phase evolution of $\mathrm{Ni} / \mathrm{Cr} / \mathrm{SiC}$ reaction couple with respect to the longer anneal time ( $>40 \mathrm{~h})$, the same reaction couples were annealed $80 \mathrm{~h}$ and $120 \mathrm{~h}$ at the same temperature. The BSE image (the $\mathrm{Ni} / \mathrm{Cr} / \mathrm{SiC}$ reaction couple annealed at $80 \mathrm{~h}$ at the same temperature) is shown in Figure $9(\mathrm{~b})$. The 
product sequence is observed as $\mathrm{Ni}(\mathrm{s} . \mathrm{s}) / \mathrm{Cr}_{23} \mathrm{C}_{6} / \mathrm{Cr}_{7} \mathrm{C}_{3} / \mathrm{T}\left((\mathrm{Cr}, \mathrm{Ni})_{5} \mathrm{Si}_{3} \mathrm{C} / \mathrm{SiC}\right.$. It should be noted that the inserted $\mathrm{Cr}$ layer disappeared and $\mathrm{Cr}$ carbide layers are produced, indicating the dominant diffusion of carbon to the Cr layer. Also, Ni diffuses towards the $\mathrm{SiC}$ side, resulting that the solubility of $\mathrm{Ni}$ on the ternary phase $\left(\mathrm{Cr}_{5} \mathrm{Si}_{3} \mathrm{C}\right)$ becomes up to about $10 \mathrm{at} \%$. Also, the BSE image of $\mathrm{Ni} / \mathrm{Cr} / \mathrm{SiC}$ reaction couple annealed at $120 \mathrm{~h}$ at the same temperature is shown in Figure 9 (c). The diffusion pathway is obtained as $\mathrm{Ni}(\mathrm{s} . \mathrm{s}) / \mathrm{Cr}_{7} \mathrm{C}_{3} / \mathrm{T}\left((\mathrm{Cr}, \mathrm{Ni})_{5} \mathrm{Si}_{3} \mathrm{C} / \mathrm{SiC}\right.$. The solubility of $\mathrm{Ni}$ on the ternary phase $\left(\mathrm{Cr}_{5} \mathrm{Si}_{3} \mathrm{C}\right)$ is observed up to 13 at $\%$. Also, the concentration of $\mathrm{Ni}$ increased and decreased through the $(\mathrm{Cr}, \mathrm{Ni})_{5} \mathrm{Si}_{3} \mathrm{C}$ phase, indicating that the $\mathrm{Ni}$ diffusion was fast enough to reach the $\mathrm{SiC}$ phase. However, the low solubility of $\mathrm{Ni}$ on $\mathrm{SiC}$ may disturb the Ni diffusion towards the $\mathrm{SiC}$ side. It should be noted that the $\mathrm{Cr}_{23} \mathrm{C}_{6}$ phase is not observed in this reaction couple. This may be due to the insufficient amount of $\mathrm{Cr}$ to maintain the $\mathrm{Cr}_{23} \mathrm{C}_{6}$ phase during interdiffusion reaction, so that the diffusion pathway is moved away from $\mathrm{Cr}$. It is clear that the diffusion pathway moves away from the $\mathrm{Cr}$ side by increasing the annealing time. For the $\mathrm{Cr}$ biased reaction couples, the reaction layers were clearly observed as a planar shape (instead of periodic layers) within experimental kinetic bounds providing a clear evidence for controlling interface morphology strategies.

Figure 9. BSE image of $\mathrm{Ni} / \mathrm{Cr} / \mathrm{SiC}$ reaction couple annealed at $900{ }^{\circ} \mathrm{C}$ for (a) $40 \mathrm{~h}$, (b) $80 \mathrm{~h}$ and (c)120 h [6].
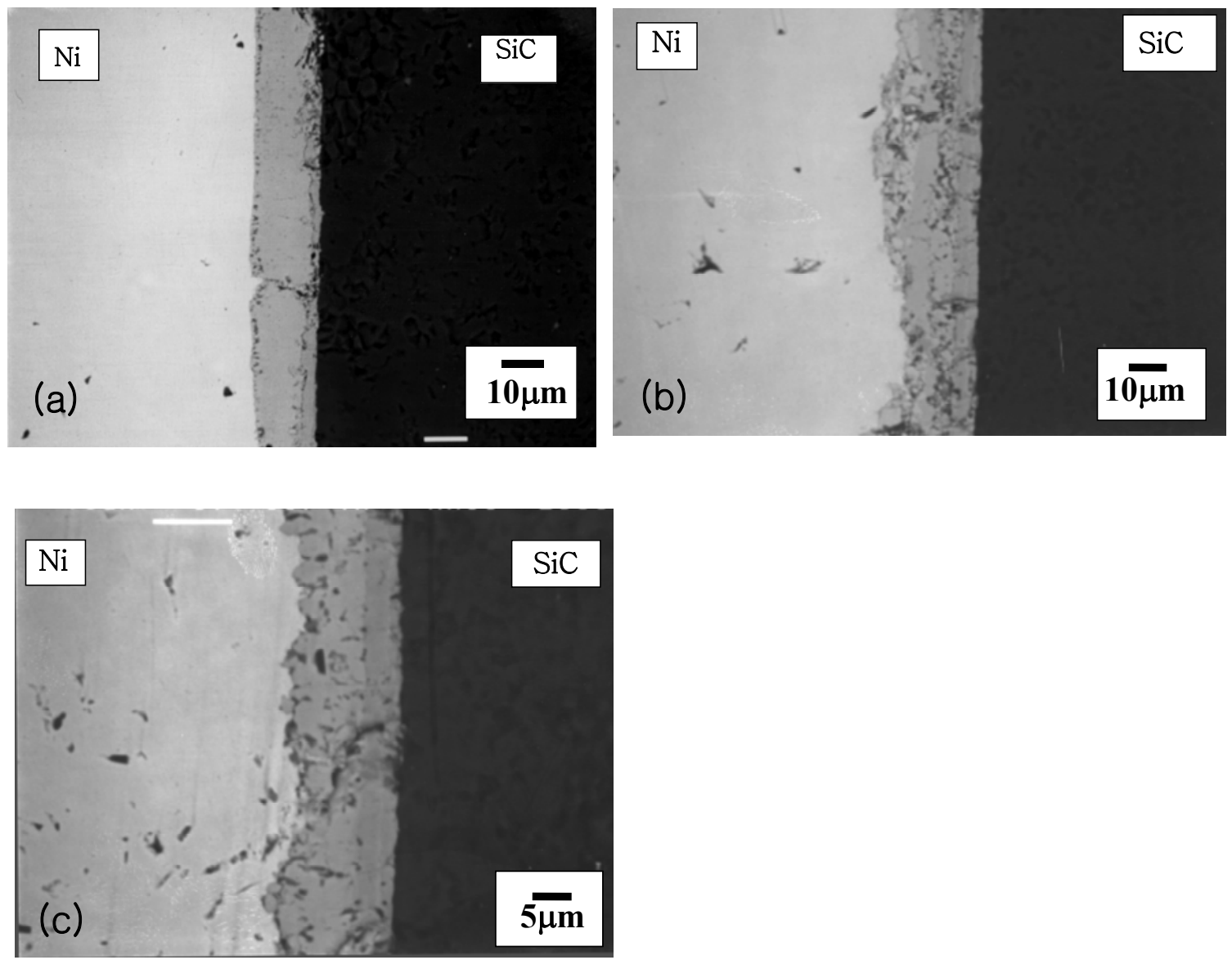


\section{Interface Reactions of TiAl/TiSi 2}

As aforementioned, another excellent example for useful practice of diffusion pathway anaylsis is the Ti-Al-Si ternary system. The back scattered image of $\mathrm{TiSi}_{2} / \gamma$-TiAl annealed at $1,100{ }^{\circ} \mathrm{C}$ for $200 \mathrm{~h}$ is shown in Figure 10. Several phases including a porous layer developed at the interface of $\mathrm{TiSi}_{2}$ and TiAl. The phase sequence was obtained as $\mathrm{TiAl} / \mathrm{TiAl}_{2} / \mathrm{Ti}_{2} \mathrm{Al}_{5} / \mathrm{TiAl}_{3}+\mathrm{Ti}_{5} \mathrm{Si}_{4} / \mathrm{Ti}_{5} \mathrm{Si}_{4} / \mathrm{TiSi} / \mathrm{TiSi}{ }_{2}$. An irregular geometry of the $\mathrm{Ti}_{5} \mathrm{Si}_{4}$ phase was developed over a $100 \mu \mathrm{m}$ layer thickness, in which the dark regions were observed as pores. It is noted that the $\mathrm{Al}$ solubility in the silicides (i.e., $\mathrm{Ti}_{5} \mathrm{Si}_{4}$ and $\mathrm{TiSi}$ ) was detected to be less than 2 at \%. However, the solubility of $\mathrm{Si}$ in the $\mathrm{TiAl}_{3}$ phase was detected to range up to $7 \mathrm{at} \%$, which is in agreement with previous results in which the large solubility of silicon in the $\mathrm{TiAl}_{3}$ phase has been reported [23].

Figure 10. Back Scattered Electron (BSE) image showing TiAl/TiSi 2 reaction couple annealed at $1,373 \mathrm{~K}$ for $200 \mathrm{~h} \mathrm{[7].}$

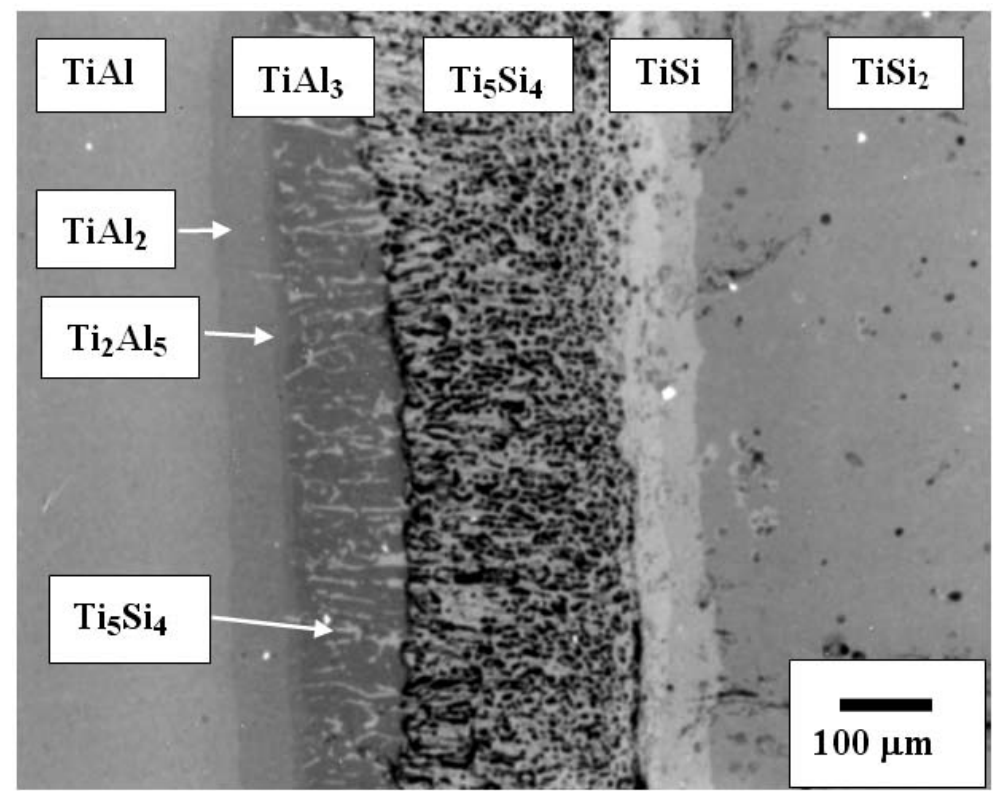

The information about partial kinetics can be obtained qualitatively from the formation of the columnar $\mathrm{Ti}_{5} \mathrm{Si}_{4}$ phase developed in the $\mathrm{TiAl}_{3}$ phase. In order to evaluate the kinetics of the movement of components from the resultant morphology, the rate limiting component has been evaluated. When initial driving force for an interdiffusion reaction is a composition difference, the $\mathrm{Ti}$ and $\mathrm{Al}$ atoms would move towards the $\mathrm{TiSi}_{2}$ side, but $\mathrm{Si}$ would diffuse in the direction of the TiAl side. The columnar zone of the $\mathrm{Ti}_{5} \mathrm{Si}_{4}$ phase grows towards the TiAl side as shown in Figure 11. If Si of the $\mathrm{Ti}_{5} \mathrm{Si}_{4}$ phase is the rate limiting component $\left(\mathrm{D}\right.$ Ti(TiAl3) $\left.>\mathrm{D}_{\mathrm{Si}(\mathrm{TiSSi} 4)}\right)$, the feeding of $\mathrm{Si}$ atoms to the columnar $\mathrm{Ti}_{5} \mathrm{Si}_{4}$ phase determines the shape of the interface. Since the interface moves towards the TiAl side, the feeding rate to the point $\mathbf{K}^{\prime}$ is faster than that to the point $\mathbf{K}$. Then, the pertubation would decay due to the faster movement of point $\square$, resulting that the planar interface develops. However, if $\mathrm{Ti}$ of the $\mathrm{TiAl}_{3}$ phase is the rate limiting component $\left(\mathrm{D}_{\mathrm{Ti}(\mathrm{TiAl} 3)}<\mathrm{D}_{\mathrm{Si}(\mathrm{Ti} 5 \mathrm{Si} 4)}\right.$ ), the arriving rate to the columnar $\mathrm{Ti}_{5} \mathrm{Si}_{4}$ phase establishes the shape of the interface. In this case, the arriving rate to 
the point $\mathbf{K}$ (the tip of the columnar $\mathrm{Ti}_{5} \mathrm{Si}_{4}$ phase) is faster than that to the point $\mathbf{K}^{\prime}$, resulting in the development of pertubations. Judging from the columnar morphology of the $\mathrm{Ti}_{5} \mathrm{Si}_{4}$ phase in Figure 10, the columnar $\mathrm{Ti}_{5} \mathrm{Si}_{4}$ phase grows through the $\mathrm{TiAl}_{3}$ phase, indicating that the rate limiting component is Titanium ( $\left.\mathrm{D}_{\mathrm{Ti}(\mathrm{TiAl} 3)}<\mathrm{D}_{\mathrm{Si}(\mathrm{Ti} 5 \mathrm{Si} 4)}\right)$.

Figure 11. The development of the planar or columnar interface with respect to the rate limiting component (a) the decay of the pertubation when the rate limiting component is $\mathrm{Si}$ (The feeding rate to the point $\mathbf{K}^{\prime}$ is faster than that to the point $\mathbf{K}(\mathrm{b})$ the development of pertubation when the rate limiting component is $\mathrm{Ti}$ (The arriving rate to the point $\mathbf{K}$ is faster than that to the point $\mathbf{K}^{\prime}$ ) [7].

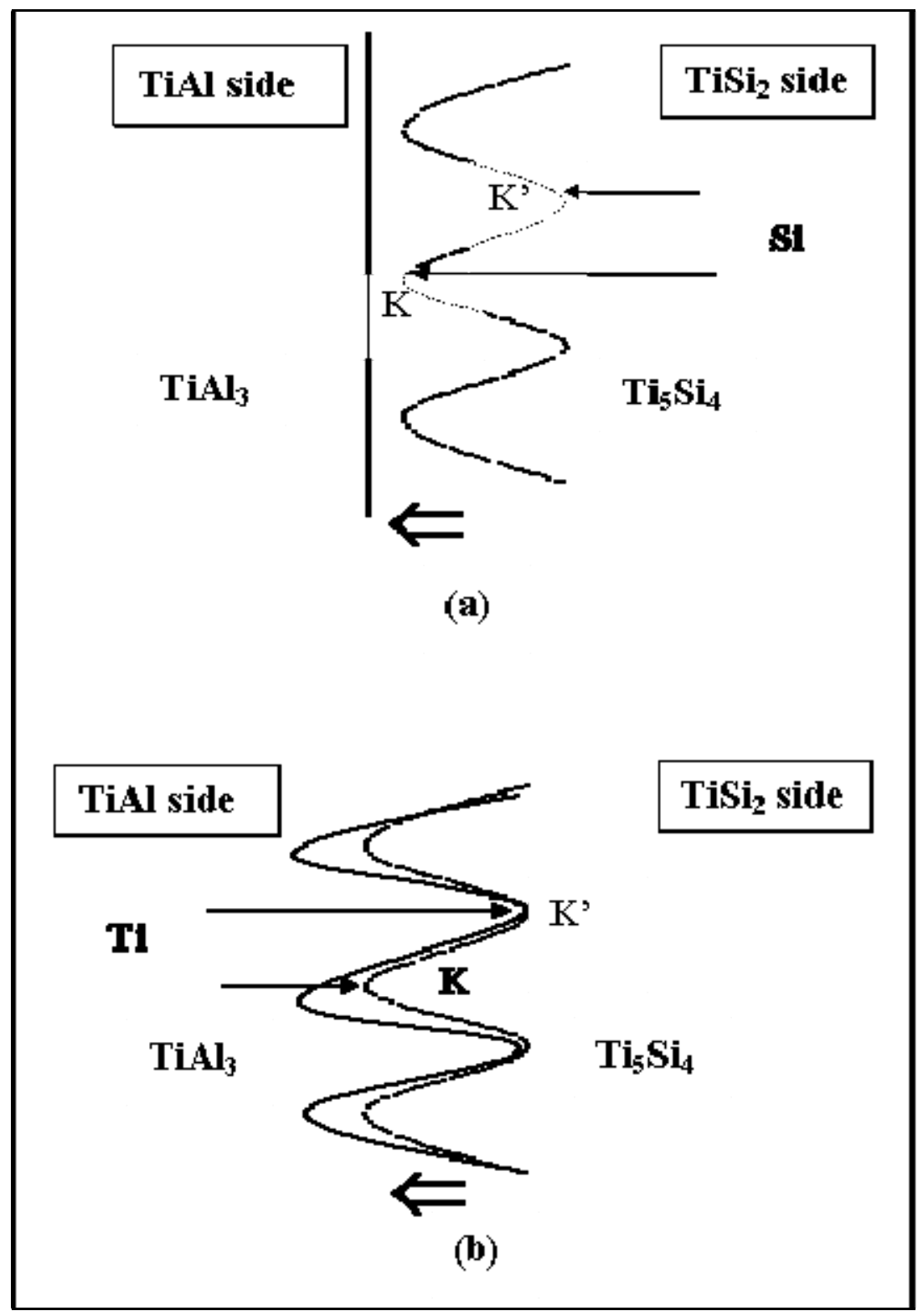


To obtain the kinetic mode of each phase, the thickness $(\xi)$ of the product phases was examined as a function of the annealing time. When the intermediate phases grow by diffusion control, the kinetics follow a parabolic law $\left(\xi^{2}=\mathrm{k} t\right)$. The estimated results show that the thickness $(\xi)$ of the intermediate phases followed the parabolic law (Figure 12). Compared with the growth rate of other phases, the growth rate of $\mathrm{Ti}_{5} \mathrm{Al}_{4}$ showed the largest sensitivity to the annealing time. Even though the $\mathrm{Ti}_{5} \mathrm{Si}_{4}$ phase was developed as a porous structure, the growth rate shows the same order of magnitude as that of the TiSi and $\mathrm{TiAl}_{3}$ phases, and the growth rate of the $\mathrm{Ti}_{2} \mathrm{Al}_{5}$ phase showed the lowest among the product phases.

Figure 12. The growth of each product phase of $\mathrm{TiSi}_{2} / \mathrm{TiAl}$ reaction couples annealed at $1,373 \mathrm{~K}[7]$.

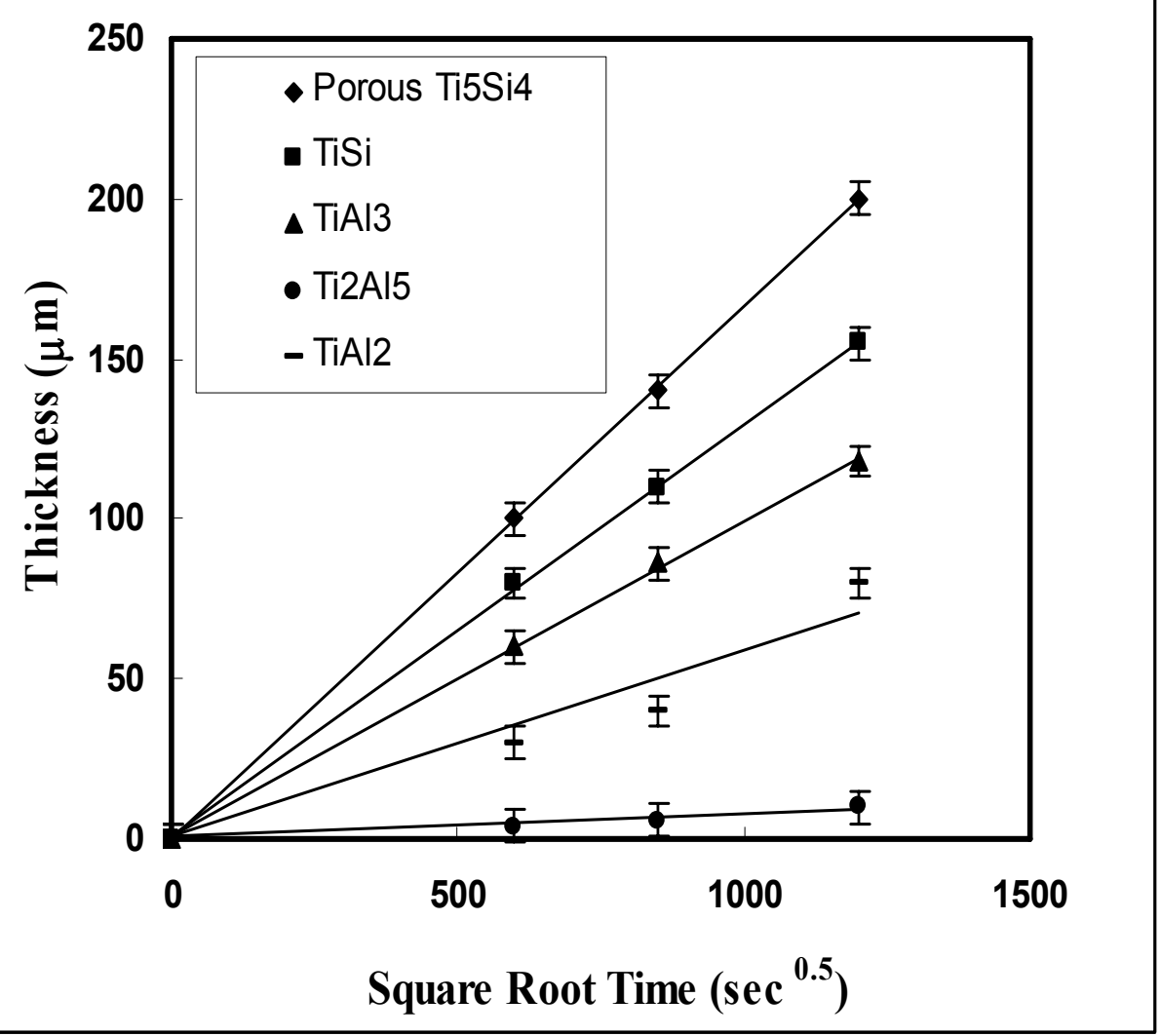

Since the titanium aluminide products show a limited Si solubility, it is useful to compare them with the growth in the binary system. It has been reported that most of the intermetallic phases such as $\mathrm{Ti}_{3} \mathrm{Al}$, TiAl, $\mathrm{TiAl}_{2}$ and $\mathrm{Ti}_{2} \mathrm{Al}_{5}$ do not follow a parabolic law due to the influence of grain boundary diffusion with an exception of the $\mathrm{TiAl}_{3}$ phase which follows a parabolic law [57,58]. However, Hirano and Iijima [59] reported that as a result of diffusion annealing of $\beta$-Ti/TiAl couples, the Ti rich product phases $\left(\alpha-\mathrm{Ti}, \beta-\mathrm{Ti}\right.$ and $\left.\mathrm{Ti}_{3} \mathrm{Al}\right)$ are controlled by volume diffusion (following the parabolic law) at long annealing time (more than $200 \mathrm{~h}$ ). Also, it has been pointed out that the reason for grain boundary diffusion in the Ti-Al system is due to the short annealing time [59]. Therefore, based upon the above results, it is considered that when the reaction couples are examined at long term annealing, the 
parabolic growth mode is also dominant in the binary Ti-Al system. In this study, all of the product phases followed a parabolic law in agreement with the previous report [59].

The growth kinetics of the silicide formation also has been examined by Cockeram et al. [60]. The parabolic rate constants of TiSi and $\mathrm{Ti}_{5} \mathrm{Si}_{4}$ phase have been estimated as $1.19 \times 10^{-10} \mathrm{~cm}^{2} / \mathrm{sec}$ and $5.44 \times 10^{-11} \mathrm{~cm}^{2} / \mathrm{sec}$, respectively, after Ti/Si diffusion annealing at 1,373 $\mathrm{K}$. While it has been reported that the growth rate of $\mathrm{TiSi}$ was larger than that of $\mathrm{Ti}_{5} \mathrm{Si}_{4}[58]$, the current study shows that the growth rate of $\mathrm{Ti}_{5} \mathrm{Si}_{4}$ was larger than that of the TiSi phase. In fact, the estimated rate constants of the TiSi and $\mathrm{Ti}_{5} \mathrm{Si}_{4}$ phase were obtained as $1.58 \times 10^{-10} \mathrm{~cm}^{2} / \mathrm{sec}$ and $2.67 \times 10^{-10} \mathrm{~cm}^{2} / \mathrm{sec}$ respectively, indicating that the growth rate of $\mathrm{Ti}_{5} \mathrm{Si}_{4}$ has been increased about one order of magnitude higher than that of the previous report [60]. It seems that this behavior is due to the effect of the third element (the effect of $\mathrm{Al}$ on the growth of $\mathrm{Ti}_{5} \mathrm{Si}_{4}$ phase).

In the reactive diffusion, the thicknesses of the product phases are related to the interdiffusion coefficients. However, when an intermetallic compound with a very narrow homogeneity range forms during reactive diffusion, the measurement of a concentration gradient is virtually not possible, because the concentration gradients of components does not develop clearly. In order to evaluate the diffusivity for an intermetallic compound having a limited solubility, Wagner [61] introduced an integrated diffusion coefficient, $\mathrm{D}_{\text {int, }}$, which is defined as an integrated value of the interdiffusion coefficient over its (unknown) limits of homogeneity between N' and N" (mole fraction) and expressed as follows:

$$
D_{\text {int }}=\int_{N^{\prime}}^{N^{\prime \prime}} \widetilde{D} d N
$$

For the case of producing several phases with a very narrow homogeneity region, the integrated diffusion coefficient of phase $i$ can be written as in Equation (5):

$$
D_{\text {int }}^{i}=A+B
$$

where $A=\left(N^{i}-N^{-}\right) \frac{\left(N^{+}-N^{i}\right)}{N^{+}-N^{-}} \frac{\left(\Delta x^{i}\right)^{2}}{2 t}$ and:

$$
\begin{aligned}
& B=\frac{\Delta x^{i}}{2 t} *\left[\frac{\left(N^{+}-N_{i}\right) \sum_{v=2}^{v=i-1} \frac{V_{m}^{i}}{V_{m}^{v}}\left(N^{v}-N^{-}\right) \Delta x^{v}+\left(N^{i}-N^{-}\right) \sum_{v=i-1}^{v=n-1} \frac{V_{m}^{i}}{V_{m}^{v}}\left(N^{+}-N^{v}\right) \Delta x^{v}}{N^{+}-N^{-}}\right] \\
& \quad \mathrm{N}^{+(-)}: \text {mole fraction at }+\infty(-\infty) \\
& \quad \mathrm{V}_{\mathrm{m}}: \text { molar volume } \\
& \Delta \mathrm{x}^{\mathrm{i}}: \text { thickness of } \mathrm{i} \text { phase } \\
& \mathrm{t}: \text { time }
\end{aligned}
$$

Based upon the above equation, the integrated diffusivity of phases can be obtained if thicknesses and compositions are known. Assuming that the molar volume does not change from one phase to another, Equation (5) can be expressed in a simpler form [20]. For the case of an A/B reaction couple producing three line compounds, $\alpha, \gamma$ and $\delta$, the integrated diffusivity of $\gamma$ is written as Equation (6): 


$$
D_{\mathrm{int}}^{\gamma}=\left[\frac{a \times b}{a+b}\right] * \frac{\Delta x_{\gamma}^{2}}{2 t}+\frac{\Delta x_{\gamma}}{2 t} *\left[\frac{b \times P+a \times Q}{a+b}\right]
$$

where $P$ and $Q$ equal the hatched areas in Figure 13 and $a=N_{A}^{\gamma}-N_{A}{ }^{-}$and $b=N_{A}{ }^{+}-N_{A}^{\gamma}$, respectively.

Figure 13. The schematic concentration profile of $\mathrm{A} / \mathrm{B}$ diffusion couple produced $\beta, \delta$ and $\gamma[7]$.

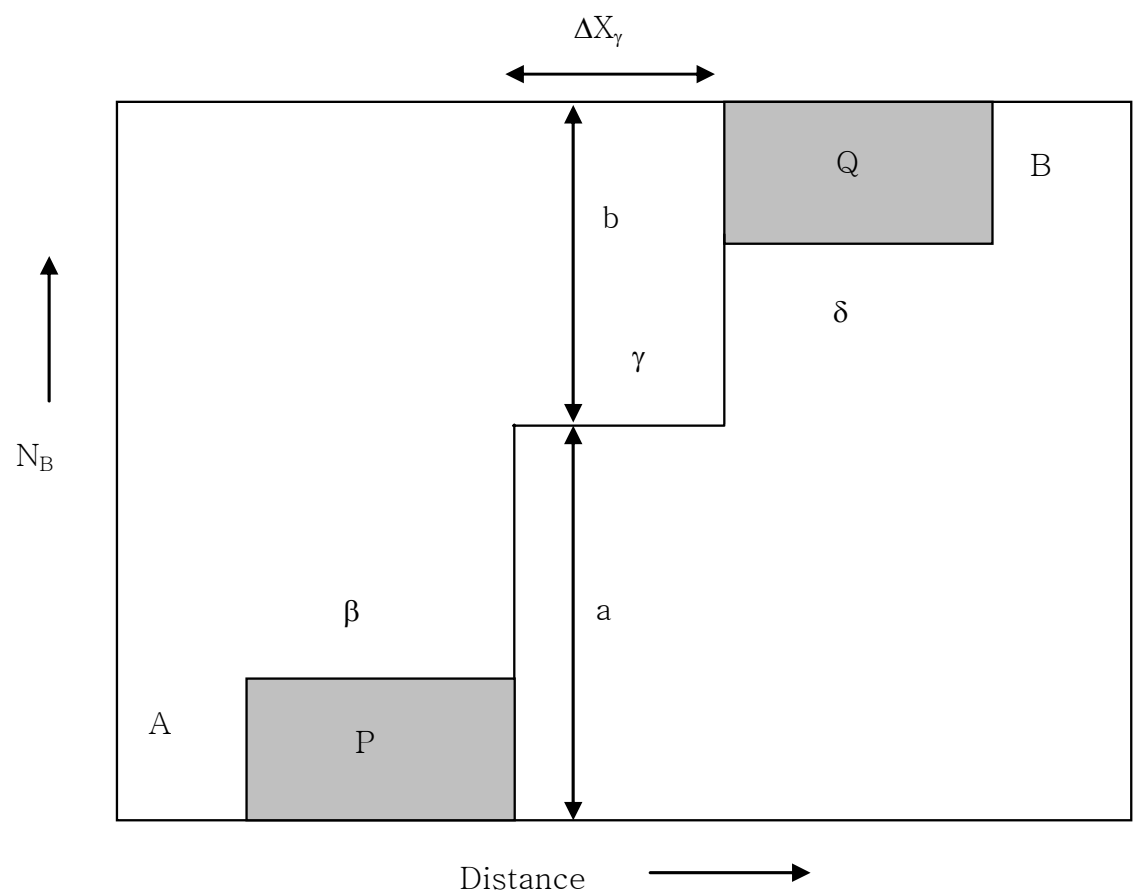

The integrated diffusivity of the current reaction couple has been estimated based upon the observed product layer thickness. When applying the above equation, the porous layer has been approximated as a solid layer as a line compound. The estimated parameters of Equation 3 and the integrated diffusion coefficient are shown in Table 3 . The diffusion coefficient of $\mathrm{Ti}_{2} \mathrm{Al}_{5}$ marks the lowest value. Since the integrated diffusion coefficient corresponds to the integral values of the interdiffusion coefficient as defined previously, it is considered that the low value of $\mathrm{Ti}_{2} \mathrm{Al}_{5}$ is due to the relatively small thickness of the phase $(\Delta X)$.

Table 3. The estimated integrated diffusion coefficients and the related parameters.

\begin{tabular}{cccccc}
\hline Phases & $\begin{array}{c}\text { Parameter } \\
\text { 'a' }\end{array}$ & $\begin{array}{c}\text { Parameter } \\
\text { 'b' }\end{array}$ & $\begin{array}{c}\text { Area } \\
\mathbf{P}\end{array}$ & $\begin{array}{c}\text { Area } \\
\mathbf{Q}\end{array}$ & $\begin{array}{c}\mathbf{D}^{\text {int }} \\
\left(\mathbf{m}^{2} / \mathbf{s e c}\right)\end{array}$ \\
\hline $\mathrm{TiSi}$ & 0.5 & 0.16 & $6.30 \times 10^{-5}$ & - & $1.76 \times 10^{-15}$ \\
$\mathrm{Ti}_{5} \mathrm{Si}_{4}$ & 0.45 & 0.21 & - & $1.60 \times 10^{-5}$ & $2.78 \times 10^{-15}$ \\
$\mathrm{TiAl}_{3}$ & 0.25 & 0.25 & $1.27 \times 10^{-4}$ & $6.39 \times 10^{-6}$ & $4.79 \times 10^{-15}$ \\
$\mathrm{Ti}_{2} \mathrm{Al}_{5}$ & 0.286 & 0.214 & $1.48 \times 10^{-4}$ & $5.10 \times 10^{-6}$ & $2.58 \times 10^{-16}$ \\
$\mathrm{TiAl}_{2}$ & 0.33 & 0.17 & $1.50 \times 10^{-4}$ & - & $1.31 \times 10^{-15}$ \\
\hline
\end{tabular}


Since the sequence of the formation of the product phases are closely related to the movement of components, it is useful to examine the kinetic features of the product phases. The schematic figure of the reaction products is given in Figure 14. It should be noted that the $\mathrm{TiAl}_{2}, \mathrm{Ti}_{2} \mathrm{Al}_{5}, \mathrm{TiAl}_{3}$ and porous $\mathrm{Ti}_{5} \mathrm{Si}_{4}$ were observed at the TiAl side, but TiSi formed at the $\mathrm{TiSi}_{2}$ side based upon the initial placement of the interface (laboratory reference frame).

Figure 14. The schematic illustration of the reaction products and the placement of the laboratory reference frame (not put to a scale) (a) before reaction, (b) after reaction.

(a)

\section{Laboratory reference frame}

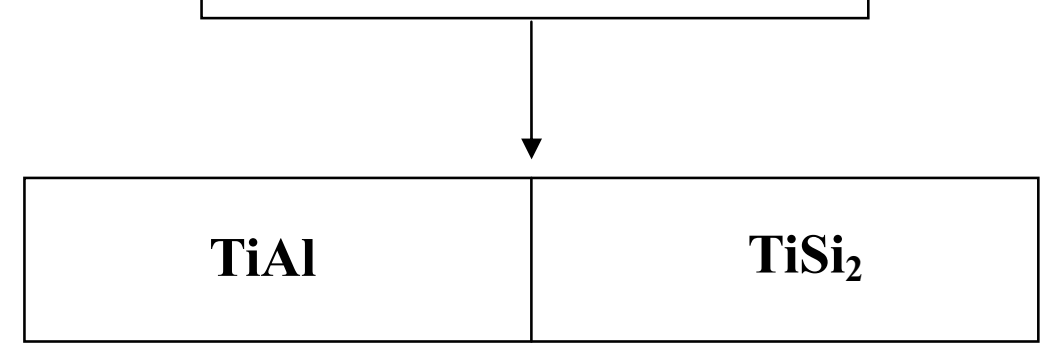

(b)

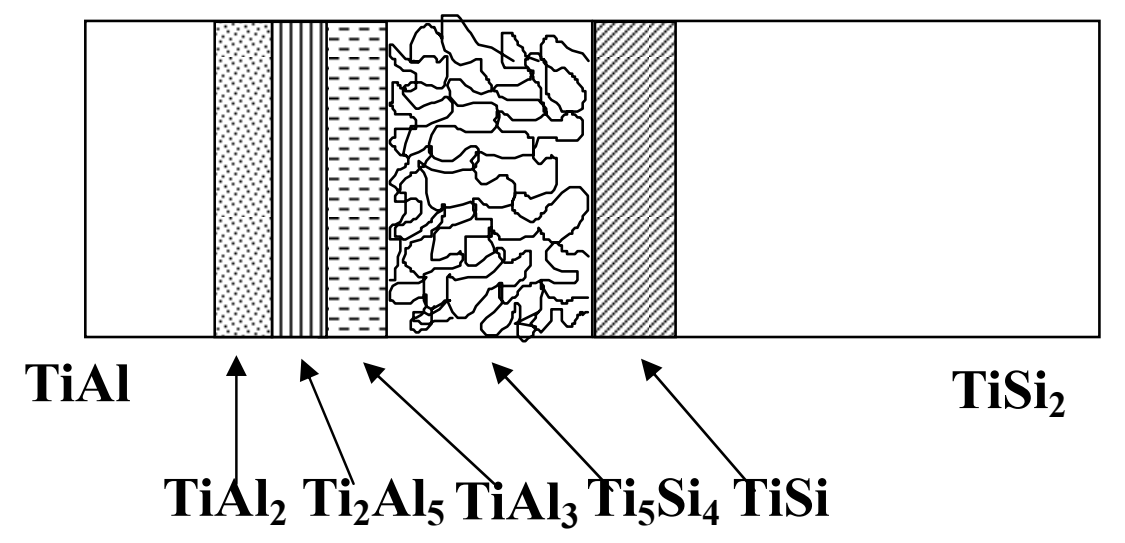

Under an assumption that the concentration difference is the initial driving force, $\mathrm{Si}$ of the $\mathrm{TiSi}_{2}$ phase would diffuse towards the TiAl side and both $\mathrm{Ti}$ and $\mathrm{Al}$ of the TiAl phase would move towards $\mathrm{TiSi}_{2}$ side. The diffusion of Si produces the TiSi phase (lower $\mathrm{Si}$ concentration) on the $\mathrm{TiSi}_{2}$ side. Also, the movement of $\mathrm{Si}$ is the reason for the formation of the $\mathrm{Ti}_{5} \mathrm{Si}_{4}$ phase, since $\mathrm{Si}$ is the only source of the silicides for this reaction couple. The formation of the porous $\mathrm{Ti}_{5} \mathrm{Si}_{4}$ phase on the TiAl side implies that the movement of $\mathrm{Si}$ in the $\mathrm{TiSi}_{2}$ phase is faster than that of $\mathrm{Ti}$ in the TiAl. Otherwise, the porous $\mathrm{Ti}_{5} \mathrm{Si}_{4}$ phase would form in the $\mathrm{TiSi}_{2}$ side. The higher Ti concentration of the porous $\mathrm{Ti}_{5} \mathrm{Si}_{4}$ phase than that of the TiAl phase indicates that $\mathrm{Ti}$ of $\mathrm{TiAl}$ diffuses towards the $\mathrm{Ti}_{5} \mathrm{Si}_{4}$ phase on the TiAl side, resulting in the formation of $\mathrm{Al}$ rich products next to the porous $\mathrm{Ti}_{5} \mathrm{Si}_{4}$ phase such as $\mathrm{TiAl}_{2}, \mathrm{Ti}_{2} \mathrm{Al}_{5}$ and $\mathrm{TiAl}_{3}$ on the TiAl side. Regarding to the diffusion behavior of $\mathrm{Al}$, it should be noted that the porous $\mathrm{Ti}_{5} \mathrm{Si}_{4}$ phase which has little solubility of Al is produced in the TiAl side. Since Al of TiAl existed initially (later occupied by the $\mathrm{Ti}_{5} \mathrm{Si}_{4}$ phase) and the reaction front of the porous $\mathrm{Ti}_{5} \mathrm{Si}_{4}$ phase moves towards the TiAl 
side, there are two possibilities to develop the porous $\mathrm{Ti}_{5} \mathrm{Si}_{4}$ phase. (a) When the $\mathrm{Ti}_{5} \mathrm{Si}_{4}$ phase grows towards the TiAl side, $\mathrm{Al}$ is trapped by the $\mathrm{Ti}_{5} \mathrm{Si}_{4}$ phase, finally evaporated and the traces of $\mathrm{Al}$ are observed as pores. (b) Since Al can not diffuse towards the $\mathrm{Ti}_{5} \mathrm{Si}_{4}$ phase (low solubility of $\mathrm{Al}$ in the $\mathrm{Ti}_{5} \mathrm{Si}_{4}$ phase), the excess Al does diffuse backwards. Finally, Kirkendall voids due to this flux imbalance initiate the development of pores.

In order to investigate the formation mechanism of the porous layer, cold pressed powder mixtures of $\mathrm{TiSi}_{2}$ and $\mathrm{TiAl}$ were vacuum sealed and annealed at $1,100{ }^{\circ} \mathrm{C}$ for $30 \mathrm{~h}$ followed by an air cooling (Figure 15). Several products and porous $\mathrm{Ti}_{5} \mathrm{Si}_{4}$ phase were observed, which is consistent with the $\mathrm{TiSi}_{2} / \mathrm{TiAl}$ reaction couple. While porous layers were found, a clear evidence for the traces of an excess $\mathrm{Al}$ has not been found. Therefore, it can be drawn that the second mechanism (backward diffusion of $\mathrm{Al}$ ) is a main reason for the formation of the porous phase, which is in agreement with the previous results [62]. Also, for the reactive diffusion reaction, volume changes are usually involves during interdiffusion, which might contribute to form pores at the interface of $\mathrm{TiAl}_{3}$ and $\mathrm{Ti}_{5 \mathrm{Si}}$ phase together with flux imbalance.

Figure 15. The BSE image (a) and X-ray maps (with respect to (b) Al, (c) Ti and (d) Si) of $\mathrm{TiAl} / \mathrm{TiSi}_{2}$ powder mixture annealed at $1,100{ }^{\circ} \mathrm{C}$ for $40 \mathrm{~h}$ [7].

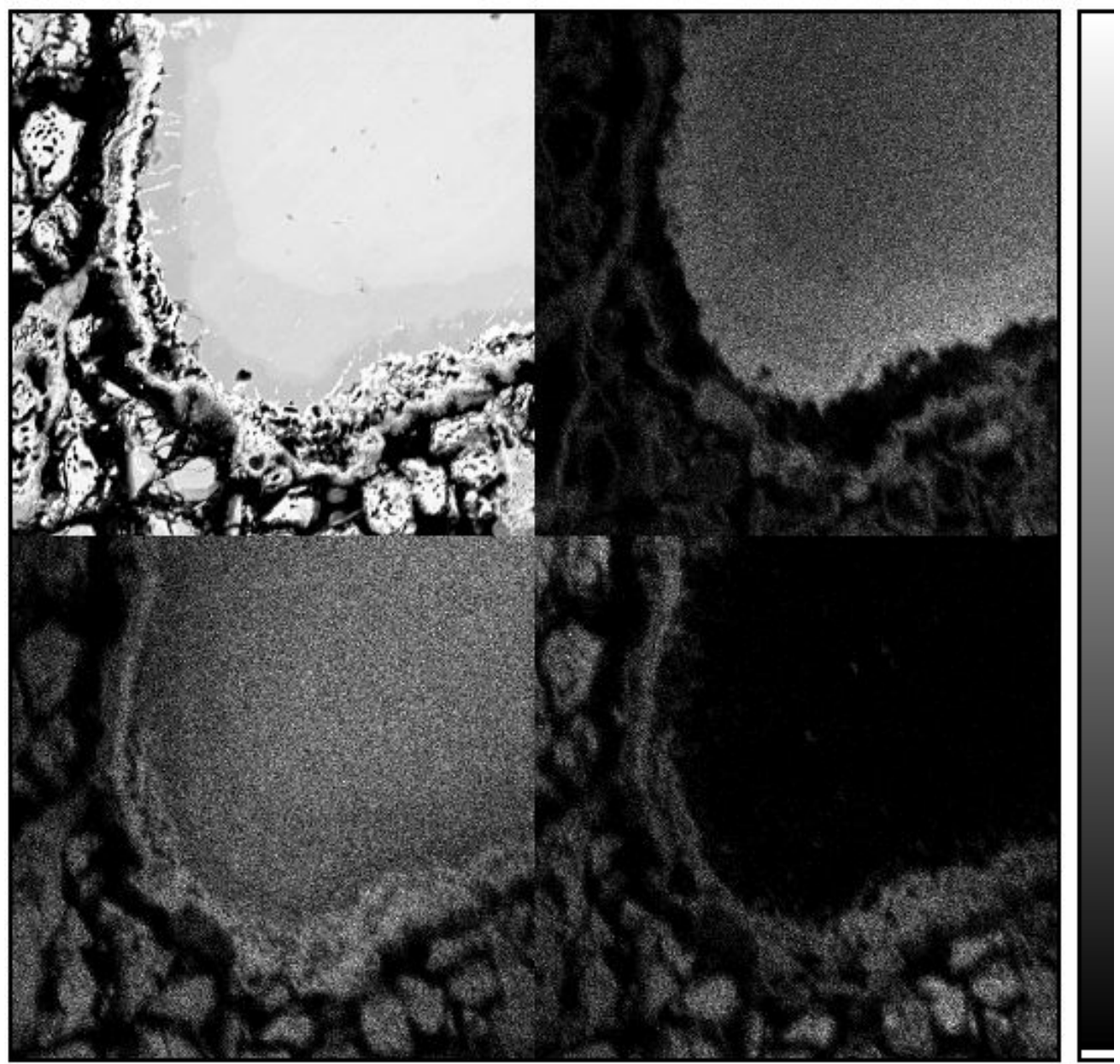

100 un BSE_Z Al Ti Si $15 \mathrm{kV} \quad 20 \mathrm{nA}$ 
In diffusion controlled reactions, each product layer grows with respect to the relative flux of neighboring phases accompanied by volume changes, resulting in the development of stress between the product phases. In order to estimate the volume change during interdiffusion processing, the binary lattice constants were employed to calculate the molar volumes, considering the low solubility of the third element in the binary compounds. The structures, volumes of the unit cells and the molar volumes of the phases in the $\mathrm{Ti}$ - $\mathrm{Si}$ and $\mathrm{Ti}-\mathrm{Al}$ system are shown in Table 4. Compared to the molar volumes of the product phases, the molar volumes of the $\mathrm{Ti}_{5} \mathrm{Si}_{4}$ and $\mathrm{Ti}_{5} \mathrm{Si}_{3}$ phases showed relatively high values. Also, the molar volume of each phase is shown based upon the observed diffusion path of $\mathrm{TiSi}_{2} / \mathrm{TiAl}$ (Figure 16). It is clear that the molar volume of the $\mathrm{Ti}_{5} \mathrm{Si}_{4}$ phase is relatively high compared to the $\mathrm{TiAl}_{3}$ and TiSi phases.

Table 4. The Crystal structures and molar volumes of the Titanium alluminides and Titanium silicides (V: volume of the unit cell, Z : Number of formula units in the unit cell) [7].

\begin{tabular}{|c|c|c|c|c|c|}
\hline Phase & Pear.sym. & prototype & $V\left(n m^{3}\right)$ & $\mathbf{Z}$ & $\begin{array}{c}\text { Mol. Vol. } \\
\left(\mathrm{cm}^{3} / \mathrm{g} \text {-atom) }\right.\end{array}$ \\
\hline$\beta-\mathrm{Ti}$ & $\mathrm{cI} 2$ & W & 0.0317 & 2 & 9.543 \\
\hline TiAl & tP4 & $\mathrm{AuCu}$ & 0.0652 & 4 & 9.813 \\
\hline $\mathrm{TiAl}_{2}$ & $\mathrm{tI} 24$ & $\mathrm{Ga}_{2} \mathrm{Hf}$ & 0.3850 & 24 & 9.667 \\
\hline $\mathrm{Ti}_{2} \mathrm{Al}_{5}$ & tI16 & $\mathrm{Al}_{3} \mathrm{Zr}$ & 0.2540 & 16 & 9.539 \\
\hline $\mathrm{TiAl}_{3}$ & $\mathrm{tI} 8$ & $\mathrm{Al}_{3} \mathrm{Ti}$ & 0.1276 & 8 & 9.598 \\
\hline$(\mathrm{Si})$ & $\mathrm{cF} 8$ & $C($ dia $)$ & 0.1600 & 12 & 12.000 \\
\hline $\mathrm{TiSi}_{2}$ & oF24 & $\mathrm{C} 54$ & 0.3394 & 24 & 8.513 \\
\hline TiSi & oP8 & TiSi & 0.1192 & 8 & 8.970 \\
\hline $\mathrm{Ti}_{5} \mathrm{Si}_{4}$ & ТP36 & $\mathrm{Si}_{4} \mathrm{Zr}_{5}$ & 0.6602 & 36 & 11.040 \\
\hline $\mathrm{Ti}_{5} \mathrm{Si}_{3}$ & hP16 & $\mathrm{Mn}_{5} \mathrm{Si}_{3}$ & 0.2835 & 16 & 10.670 \\
\hline $\mathrm{Ti}_{3} \mathrm{Si}$ & tP32 & Ti3P & 0.5280 & 32 & 9.933 \\
\hline$(\mathrm{Al})$ & $\mathrm{cF} 4$ & $\mathrm{Cu}$ & 0.0664 & 4 & 9.667 \\
\hline
\end{tabular}

The volume changes and free energy changes of the relevant reactions are shown in Table 5. The volume change ratios were calculated from the ratio of total product molar volumes to the total initial volumes. It should be noted that most of the reactions showed a large volume reduction. Especially, reaction (2) showed the largest value of the volume reduction ratio by producing $\mathrm{Ti}_{5} \mathrm{Si}_{4}$ phase from TiSi and Ti. However, reaction (6) showed a large volume expansion by producing $\mathrm{Ti}_{5} \mathrm{Si}_{4}$ from $\mathrm{TiAl}_{3}$ and Si. From the calculated results, it can be estimated that a large volume change is involved at the interfaces of the $\mathrm{Ti}_{5} \mathrm{Si}_{4}$ phase. It is considered that since $\mathrm{Ti}_{5} \mathrm{Si}_{3}$ is placed in the Ti rich side of the Ti-Si binary system, the flux of $\mathrm{Ti}$ is not sufficient to allow for the formation of $\mathrm{Ti}_{5} \mathrm{Si}_{3}$. In order to produce the $\mathrm{Ti}_{5} \mathrm{Si}_{3}$ phase, the interdiffusion reaction with the additional Ti flux has been investigated. 
Table 5. The calculated volume change ratio and reactions.

\begin{tabular}{|c|c|c|c|}
\hline No & Reactions & $\begin{array}{c}\text { Volume changeRatio } \\
(\%)\end{array}$ & $\begin{array}{c}\text { Free energy of Reaction } \\
(\mathbf{K J} / \mathbf{m o l})\end{array}$ \\
\hline 1 & $\mathrm{TiSi}_{2}+\mathrm{Ti}=2 \mathrm{TiSi}$ & -6.6 & -130.7 \\
2 & $4 \mathrm{TiSi}+\mathrm{Ti}=\mathrm{Ti}_{5} \mathrm{Si}_{4}$ & -75.7 & -61.8 \\
3 & $\mathrm{TiAl}+\mathrm{Al}=\mathrm{TiAl}_{2}$ & -50.4 & -21.4 \\
4 & $2 \mathrm{TiAl}_{2}+\mathrm{Al}=\mathrm{Ti}_{2} \mathrm{Al}_{5}$ & -67.1 & -14.1 \\
5 & $\mathrm{Ti}_{2} \mathrm{Al}_{5}+2 \mathrm{Al}=2 \mathrm{TiAl}_{3}$ & -33.5 & -12.0 \\
6 & $5 \mathrm{TiAl}_{3}+4 \mathrm{Si}=\mathrm{Ti}_{5} \mathrm{Si}_{4}+15 \mathrm{Al}$ & +62.6 & -269.2 \\
\hline
\end{tabular}

Figure 16. The molar volumes of the product phases of the $\mathrm{TiAl} / \mathrm{TiSi}_{2}$ reaction couple [7].

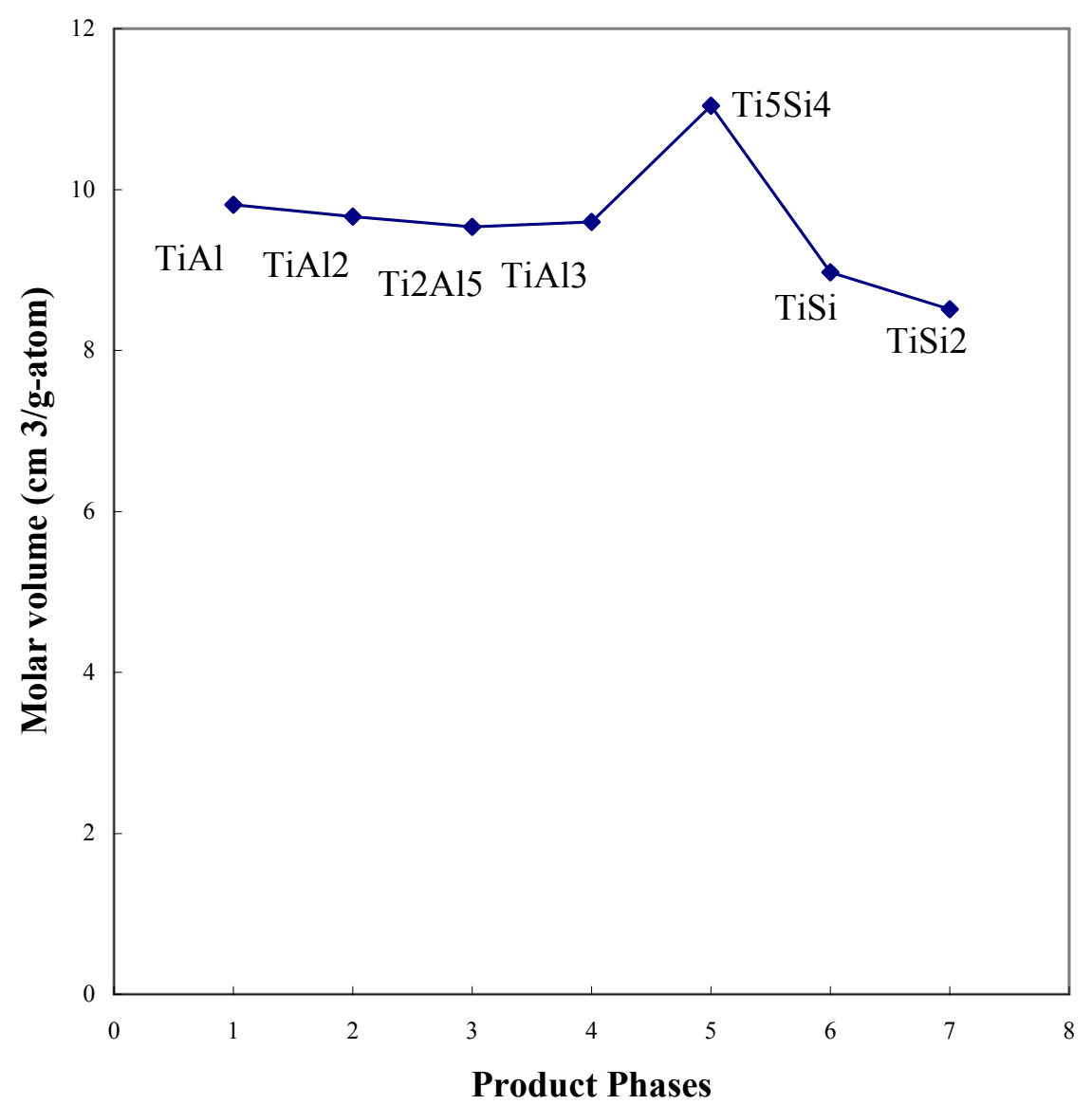

\section{Control of the Interface Reactions in $\mathrm{TiSi}_{2} / \mathrm{Ti} / \mathrm{TiAl}$}

In order to investigate the stability of the biased reaction, the $\mathrm{TiSi}_{2} / \mathrm{Ti} / \mathrm{TiAl}$ couples were annealed at $1,100{ }^{\circ} \mathrm{C}$ for $400 \mathrm{~h}$ (Figure 17). It should be noted that the porous $\mathrm{Ti}_{5} \mathrm{Si}_{4}$ phase was not developed in the biased diffusion couple, and the expected $\mathrm{Ti}_{5} \mathrm{Si}_{3}$ phase was successfully produced. For the case of the $200 \mathrm{~h}$ annealed sample (not shown), the thickness of the $\mathrm{Ti}_{5} \mathrm{Si}_{3}$ and $\mathrm{Ti}_{5} \mathrm{Si}_{4}$ phases were about $10 \mu \mathrm{m}$ and $40 \mu \mathrm{m}$ respectively. Compared to the reaction couples annealed for $200 \mathrm{~h}$ and for $400 \mathrm{~h}$, it should be noted that the thickness of the $\beta$-Ti phase is reduced from about $300 \mu \mathrm{m}$ (200 h annealed couple) to about $260 \mu \mathrm{m}$ (400 $\mathrm{h}$ annealed couple). The concentration of $\mathrm{Al}$ in the $\mathrm{Ti}_{5} \mathrm{Si}_{3}$ phase was detected as 
about 5 at $\%$ and the solubility of the $\mathrm{Al}$ in the $\mathrm{Ti}_{5} \mathrm{Si}_{4}$ phase was extremely small, which is the same result as the $\mathrm{TiSi}_{2} / \mathrm{TiAl}$ reaction couple. Moreover, it is clear that the concentration of the $\mathrm{Al}$ is increased in the $\mathrm{Ti}_{5} \mathrm{Si}_{3}$ phase, then abruptly decreases in front of the $\mathrm{Ti}_{5} \mathrm{Si}_{4}$ phase. This concentration variation of the Al indicates two possibilities. Since the solubility of $\mathrm{Al}$ in the $\mathrm{Ti}_{5} \mathrm{Si}_{4}$ phase is low, the $\mathrm{Ti}_{5} \mathrm{Si}_{4}$ phase serves as a barrier for the diffusion of the Al, resulting in the pile up of the Al in front of the $\mathrm{Ti}_{5} \mathrm{Si}_{4}$ phase. The other possible reason for the concentration variation is due to the nature of the diffusion pathway in a ternary system (i.e., concentration up and down during the interdiffusion in a ternary system).

Figure 17. BSE image of $\mathrm{TiSi}_{2} / \mathrm{Ti} / \mathrm{TiAl}$ reaction couple annealed for $1,100{ }^{\circ} \mathrm{C}$ for $400 \mathrm{~h}$ [7].

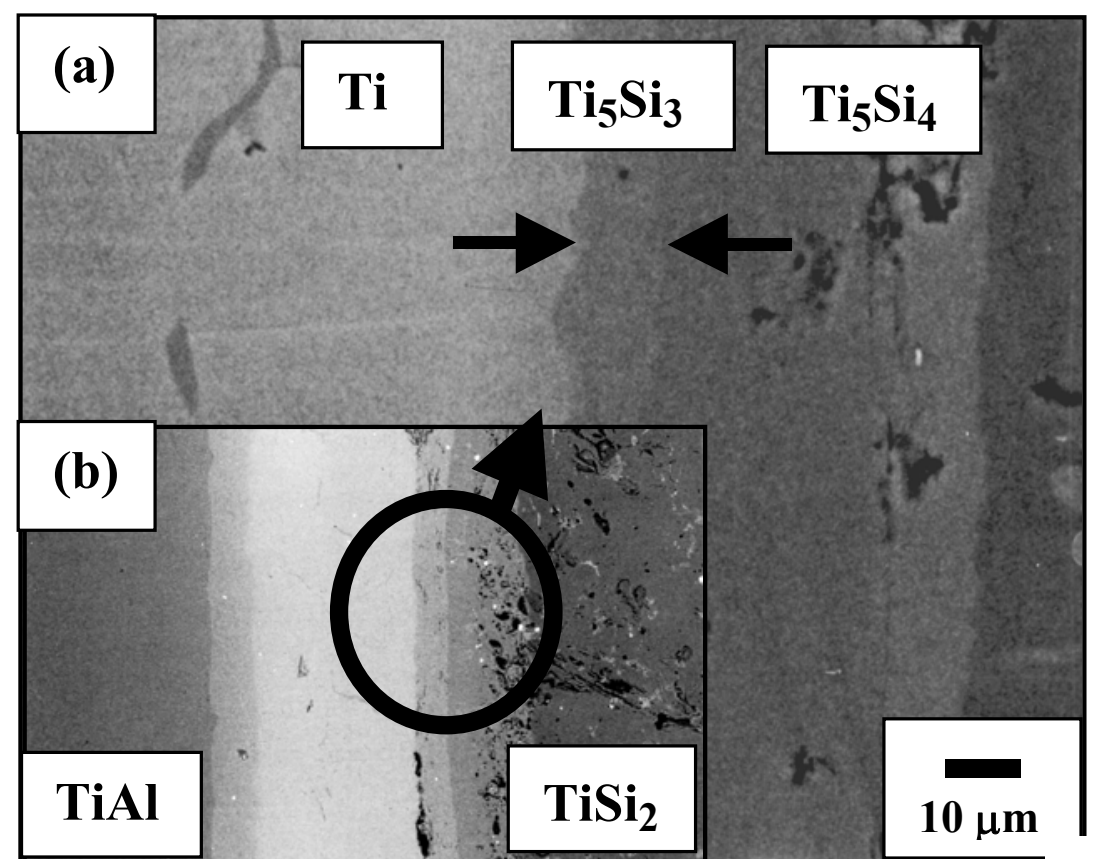

In the modified reaction couples, the $\mathrm{Ti}_{5} \mathrm{Si}_{3}$ phase was produced and the pores of the $\mathrm{Ti}_{5} \mathrm{Si}_{4}$ phase disappeared as well. The porous phase appeared at the interface of the $\mathrm{TiAl}_{3}$ and $\mathrm{Ti}_{5} \mathrm{Si}_{4}$ phases due to the flux imbalance associated with volume changes. Moreover, the interface shape of the $\mathrm{Ti}_{5} \mathrm{Si}_{4}$ and $\beta$ Ti was observed as planar. Therefore, it is concluded that the pores and the morphology can be controlled by applying the modified reaction.

\section{Reaction Pathway Analysis of the Ti-Al-Si System}

The direction of reaction pathway can be analyzed qualitatively by considering both mass balance and reaction barrier effects. In the reactive diffusion of the $\mathrm{TiSi}_{2}$ and $\mathrm{TiAl}$, only $\mathrm{Si}$ atoms in the $\mathrm{TiSi}_{2}$ phase would move towards the TiAl phase side, however, both Ti and Al atoms in the TiAl phase would diffuse towards the $\mathrm{TiSi}_{2}$ phase side due to the initial concentration difference. For the $\mathrm{Si}$ diffusion in the $\mathrm{TiSi}_{2}$ phase, only $\mathrm{Si}$ atoms would move towards the TiAl phase, resulting in the formation of the titanium rich phases such as the $\mathrm{Ti}_{5} \mathrm{Si}_{3}, \mathrm{Ti}_{5} \mathrm{Si}_{4}$ and $\mathrm{TiSi}$ in the $\mathrm{TiSi}_{2}$ side. Therefore, in order to satisfy mass balance, aluminum rich phases such as $\mathrm{TiAl}_{3}$ and $\mathrm{Ti}_{2} \mathrm{Al}_{5}$ should form on the TiAl 
phase side of the reaction couple. As a result of the diffusion reaction of $\mathrm{TiSi}_{2}$ and $\mathrm{TiAl}$, the actual product phases were obtained as follows:

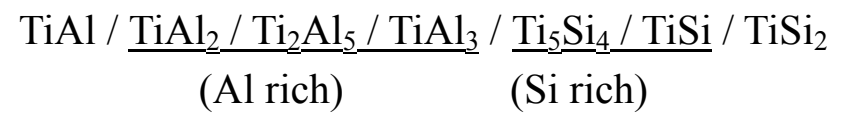

From the produce phase developed, the Si rich product phases determine the initial direction and the Al rich product phases satisfy the mass balance.

Figure 18. The stability diagram of Ti-Ai-Si ternary system with respect to (a) Ti (b)Al and (c) $\mathrm{Si}$ (Solid line: $\mathrm{TiSi}_{2} / \mathrm{TiAl}$, dotted line: $\mathrm{TiSi}_{2} / \mathrm{Ti} / \mathrm{TiAl}$ ) [7].
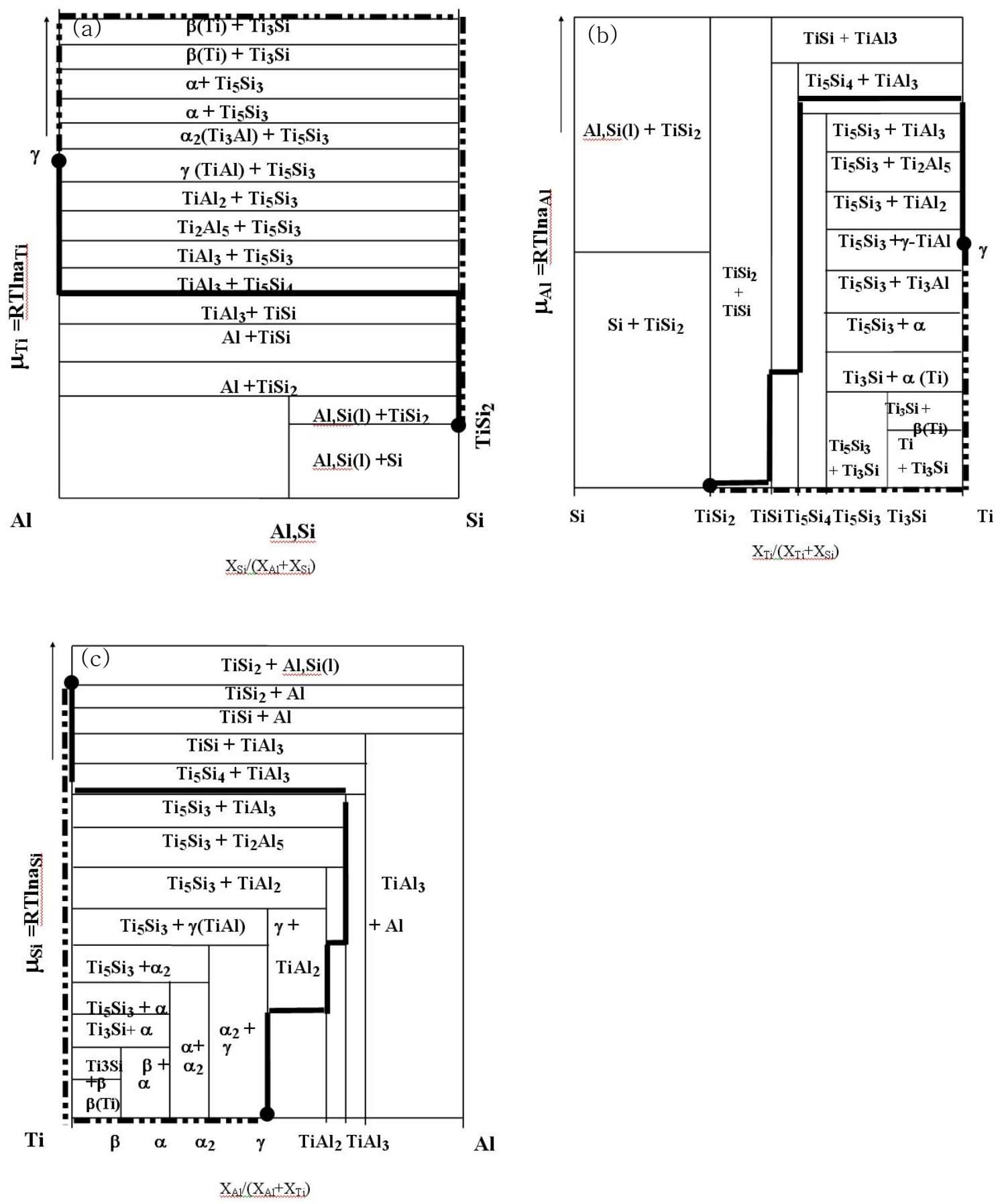
Although the $\mathrm{Ti}_{5} \mathrm{Si}_{3}$ phase was not produced, the direction of the reaction pathway followed mass balance. The reaction pathway can be also understood by the reaction barrier effect. In the diffusion reaction of the $\mathrm{Ti}-\mathrm{Al}$ system, the element $\mathrm{Al}$ has higher intrinsic diffusivity than the element $\mathrm{Ti}$ in the TiAl phase [57]. Based upon the binary results, the Al will move out the TiAl phase and yield titanium rich phases. However, the $\mathrm{Al}$ atoms become piled up in front of the $\mathrm{Ti}_{5} \mathrm{Si}_{4}$ phase due to the small solubility of $\mathrm{Al}$ in the titanium silicides for the current observations. It is considered that the $\mathrm{Al}$ contributed to the growth of the $\mathrm{TiAl}_{3}$ phase which is the $\mathrm{Al}$ rich phase. Actually, little aluminum is detected by EPMA in the $\mathrm{Ti}_{5} \mathrm{Si}_{4}$ region, resulting that the low solubility of the $\mathrm{Al}$ in the $\mathrm{Ti}_{5} \mathrm{Si}_{4}$ phase makes the diffusion of $\mathrm{Al}$ through the reaction zone difficult. Namely, the produced phase, $\mathrm{Ti}_{5} \mathrm{Si}_{4}$, which has no solubility of $\mathrm{Al}$, may serve as a barrier to prevent $\mathrm{Al}$ diffusion to the $\mathrm{TiSi}_{2}$ side. It is interesting to note that the formation of a phase with low solubility for a ternary component results in a naturally built-in reaction barrier in the diffusion process. A similar effect has been reported for the reaction of the $\mathrm{Ni}_{3} \mathrm{Al}$ and $\mathrm{SiC}$ where the backward diffusion of the $\mathrm{Al}$ atoms occur [63], implying that the diffusion of components is affected by the solubility of the product phases.

In order to investigate the chemical potential effect, the reaction pathway was indicated in the chemical potential diagram. Based upon the isothermal phase diagram, the free energy tangential diagram is initially constructed, as shown in Figure 18. It should be noted that the tangential plane is closely related to the isothermal phase diagram together with free energy values. Then, the stability diagrams with respect to the isothermal phase diagram (phase equilibria) were constructed based upon the estimated free energy as shown in Figures 18 (a), (b) and (c) with respect to $\mathrm{Ti}, \mathrm{Al}$ and $\mathrm{Si}$, respectively. The reaction pathway was marked in the stability diagram in order to visualize the developed diffusion pathway and the chemical potential variation. The solid lines indicate the reaction pathway of the $\mathrm{TiSi}_{2} / \mathrm{TiAl}$, and the dotted lines mark the reaction pathway of the $\mathrm{TiSi}_{2} / \mathrm{Ti} / \mathrm{TiAl}$. In the reaction of the $\mathrm{TiSi}_{2} / \mathrm{TiAl}$, the diffusion pathway shows that contrary to the elements $\mathrm{Ti}$ and $\mathrm{Si}$, the chemical potential of $\mathrm{Al}$ was increased in the $\mathrm{TiAl}_{3}$ phase region. However, in the reaction of the $\mathrm{TiAl} / \mathrm{Ti} / \mathrm{TiSi}_{2}$, the chemical potential of $\mathrm{Ti}$ showed maximum in the Ti rich region. As discussed in the previously, from the thermodynamic point of view, the direction of a diffusion reaction is expected to occur with a lowering of the chemical potential. However, a reduction in chemical potential of each element is not mandated in order to reduce the overall free energy [9]. Therefore, it is clear that the chemical potential values of one component can be increased during a multiphase interdiffusion process in order to satisfy the mass balance requirement. Since the investigation of a chemical potential characterizes the diffusion pathway in a given system, the application of the diagram on the diffusion pathway and/or materials design is useful [62]. However, it should be mentioned that the current analyses works for three component systems, and the main point of the chemical potential diagram is based upon the thermodynamic estimation (local equilibrium), implying that this investigation provides excellent reference for estimating diffusion pathway in a semi-empirical manner.

\section{Summary}

The identification of interface reactions in composite systems is critically important, since a proper estimation of the interface reactions can control the overall properties of these systems. Furthermore, the basic identification of the interface reactions should be used for optimizing and controlling 
diffusion reactions. In this work, the critical tools for analyzing the diffusion reactions and managing the basic data has been practiced for selected SiC/Metal and Ti-Al-Si ternary systems. For example, a practice of diffusion coupling experiments can give a lot of information for successfully tailored materials selections, when a materials system undergoes interdiffusion reactions. Furthermore, the basic information can be used for controlling diffusion pathway (product phases), interdiffusion parameters, and morphology controls, considering that the interface morphology is also one critical factor for governing the overall properties of composite systems together with kinetic parameters. Also, constructed chemical potential diagrams based upon thermodynamic and kinetic background can give a critical guidance for tailoring reaction pathways. Considering that the direction of diffusion pathway is mainly affected by the mass balance effect and that is controllable, one can optimize initial reactants in order to produce stable materials combinations. It appears that the attaining of the objective product phase by controlling the initial diffusion pathway is an excellent example showing the effectiveness of the application of the effective strategy in the composite interface design.

\section{References}

1. Kamezawa, C.; Hirai, M.; Kusaka, M.; Iwami, M.; Labis J. Surface analyses of Zr (film)/4H-SiC (substrate) by synchrotron radiation induced-PEEM. Appl. Surf. Sci. 2004, 237, 607-611.

2. Vahlas, C.; Hall, I.W.; Haurie I. Investigation of interfacial reactivity in composite materials. Mater. Sci. Eng. A 2000, 259, 269-278.

3. Chelnokov, V.E.; Syrkin A.L. High temperature electronics using SiC: Actual situation and unsolved problems. Mater. Sci. Eng. B 1997, 46, 248-253.

4. Perepezko, J.H.; Bassani, M.H.; Da Silva; Park, J.S.; Edelstein A.S.; Everett R.K. Diffusional reactions in composite synthesis. Mat. Sci. Eng. A 1995, 195, 1-11.

5. Arsenault, R.J. Interfaces in metal — and intermetallic-matrix composites. Composites 1994, 25, 540-548.

6. Park, J.S.; Cho, J.; Yi, S.; Perepezko, J.H. Practical application of diffusion pathway analysis for SiC-metal reactions. Met. Mater. Int. 2006, 12, 231-238.

7. Park, J.S.; Cho, J.; Hur, B.Y.; Perepezko, J.H. Interface reactions and reaction synthesis of a high temperature composite system. Met. Mater. Int. 2007, 13, 1-12.

6. Soboyejo, W.O.; Ye, F.; Chen, L.-C.; Bahtish, N.; Schwartz, D.S.; Lederich, R.J. Effects of reinforcement morphology on the fatigue and fracture behavior of $\mathrm{MoSi}_{2} / \mathrm{Nb}$ composites. Acta Mater. 1996, 44, 2027-2041.

7. Kirkaldy, J.S.; Young, D.J. Diffusion in the Condensed State; The Institute of Metals: London, UK, 1987.

8. Andreev, A.N.; Tregubova, A.S.; Scheglov, M.P.; Syrkin, A.L.; Chelnokov, V.E. Influence of growth conditions on the structural perfection of $\beta$-SiC epitaxial layers fabricated on $6 \mathrm{H}-\mathrm{SiC}$ substrates by vacuum sublimation. Mater. Sci. Eng. B 1997, 46, 141-143.

9. An, Z.; Hirai, M.; Kusaka, M.; Iwami, M. Comparative PEEM and AES study of surface morphology and composition of $\mathrm{Cu}$ films on Si and 3C-SiC substrates. Surf. Sci. 2003, 547, 193-200. 
10. Labis, J.; Ohi, A.; Kamezawa, C.; Yoshida, K.; Hirai, M.; Kusaka, M.; Iwami, M. Surface and interface of $\mathrm{Ti}(\mathrm{film}) / \mathrm{SiC}($ substrate) system: A soft X-ray emission and photoemission electron microscopy study. Appl. Surf. Sci. 2002, 190, 521-526.

11. Chou, T.C.; Joshi, A. High temperature interfacial reactions of SiC with metals. J. Vac. Sci. Tech. A 1991, 9, 1525-1534.

12. Brydson, R.; Hofer, F.; Upadhyaya, D.; Kothleitner, G.; Ward-Close, M.; Tsakiropoulos, P.; Froes, S. On the application of energy filtering TEM in materials science II: Study of a fibre-reinforced metal matrix composite. Micron 1996, 27, 107-120.

13. Jeng, S.M.; Yang, J.M.; Graves, J.A. Effect of fiber coating on the mechanical behavior of SiC fiber-reinforced titanium aluminide composites. J. Mater. Res. 1993, 8, 905-916.

14. Zhang, R.; Gao, L.; Guo, J. Preparation and characterization of coated nanoscale $\mathrm{Cu} / \mathrm{SiC}_{\mathrm{p}}$ composite particles. Ceram. Int. 2004, 30, 401-404.

15. Tang, W.M.; Zheng, Z.X.; Ding, H. F.; Jin, Z.H. Control of the interface reaction between silicon carbide and iron. Mater. Chem. Phys. 2003, 80, 360-365.

16. Cao, Y.; Nyborg, L.; Jelvestam, U.; Yi, D. Effect of pre-treatment and nickel layer thickness on nickel silicide/silicon carbide contact. Appl. Surf. Sci. 2005, 241, 392-402.

17. Hatali, M.L.; Valette, S.; Ropital, F. ; Stremsdoerfer, G.; Mesrati, N.; Tréheux, D. Study of SiCnickel alloy bonding for high temperature applications. J. Eur. Ceram. Soc. 2009, 29, 813-819.

18. Van Loo, F.J.J.; Rijnders, M.R.; Rönkä, K.J.; Gülpen, J.H.; Kodentsov, A.A. Solid state diffusion and reactive phase formation. Solid State Ionics 1997, 95, 95-106.

19. Bhanumurthy, K.; Schmid-Fetzer, R. Interface reactions between silicon carbide and metals (Ni, Cr, Pd, Zr). Composites A 2001, 32, 569-574.

20. Ward-Close, C.M.; Minor, R.; Doorbar, P.J. Intermetallic-matrix composites-A review. Intermetallics 1996, 4, 217.

21. Zhang, L.; Qiu, G.; Wu, J. A preliminary research on the microstructure and the mechanical properties of $\mathrm{TiAl}+\mathrm{Ti}_{5} \mathrm{Si}_{3}$ dual phase alloys. Scripta, Metall. et Mater. 1995, 32, 1683-1688.

22. Vehoff, H.; Reub, S.; Vogt, W.; Specht, P. Structural Intermetallics; Darolia, R., Lewandowski, J.J., Liu, C.T., Mantin, P.L., Mirachle. D.B., Nathal, M.V., Eds.; TMS: Warrendale, PA, USA, $1993 ;$ p. 657.

23. van Loo, F.J.J.; Rieck, G.D. Diffusion in the titanium-aluminium system-I. Interdiffusion between solid Al and Ti or Ti-Al alloys. Acta Metall. 1973, 21, 61-71.

24. Lupis, C.H.P. Chemical Thermodynamics of Materials; Elsevier Science Pub.: New York, NY, USA, 1983; p. 53.

25. Crossley, F.A.; Tuner, D.H. Titanium-rich corner of the Ti-Al-Si system. Trans. Metall. Soc. AIME 1958, 212, 60-63.

26. Schob, O.; Nowtny, H.; Benesovsky, F. Die Dreistoffe (Titan, Zirkonium Hafnium)-AluminumSilizium. Planseeberichte Fuer Pulvermetallurgie 1962, 10, 65-71.

27. Raman, A.; Schbert, K. Uber den aufbau einiger TiAl3 werwandter Legierungareihen II. Untersuchungen in einigen Ti-Al-Si und T(406) in Systemen. Zeitschrift fuer Metallkunde 1965, $56,44-52$. 
28. Zakharov, A.M.; Gul'din, I.T.; Arnold, A.A.; Matsenko, Y.A. Phase equilibria in the Al-Si-Ti system in the 10-14\% Si and 0-6\% Ti concentration range. Russ. Metall. (Engl. Transl.) Metally 1988, 4, 185-189.

29. Agreeva, N.V. Al-Si-Ti phase diagram. In Diagrrammy Sostoyaniya Metallicheskikh System; Agreeva, N.V., Ed.; Viniti: Moscow, USSR, 1968; Volume 14, pp. 121-121a.

30. Handbook of Ternary Alloy Phase Diagram; Villars, P., Prince, A., Okamodo, H., Ed.; ASM International: Materials Park, OH, USA, 1995; Volume 4, p. 4311.

31. Wu, J.S.; Beaven, P.A.; Wagner, R.; Hartig, C.; Seeger, J. High-Temperature Ordered Intermetallic Alloys III; Liu, C.T., Taub, A.I., Stoloff, N.S., Koch, C.C., Eds.; MRS: Pittsburgh, PA, USA, 1989; Volume 133, p. 761.

32. Wu, J.S.; Beaven, P.A.; Wagner, R. The $\mathrm{Ti}_{3}(\mathrm{Al}, \mathrm{Si})+\mathrm{Ti}_{5}(\mathrm{Si}, \mathrm{Al})_{3}$ Eutectic Reaction in the Ti-Al-Si system. Scripta Metall., et Mater. 1990, 24, 207-212.

33. Murray, J.L.; McAlater, A.J. The AI-Si System. Bull. Alloy Phase Diag. 1984, 5, 74.

34. Murray, J.L. Phase Diagram of Binary Titanium Alloys; Murray, J.L., Ed.; ASM: Materials Park, OH, USA, 1987; p. 289.

35. Zhang, F.; Chen, S.L.; Chang, Y.A.; Kattner, U.R. A thermodynamic description of the Ti-Al system. Intermetallics 1997, 5, 471-482.

36. Chou, T.C. Interfacial debonding by solid-state reactions of SiC with Ni and Co. Scripta Metall. Mater. 1993, 29, 255-260.

37. Gulpen, J.H.; Kodentsov, A.A.; van Loo, F.J.J. Applications of Thermodynamics in the Synthesis and Processing of Materials; Nash, P., Sundman, B., Eds.; The Minerals, Metals and Materials Soc.: Warrendale, PA, USA, 1995; p. 127.

38. Warren, R.; Andersson, C.-H. Silicon carbide fibres and their potential for use in composite materials. Part II. Composites 1984, 15, 101-111.

39. Schuster, J.C. Structural Ceramics Joining II (Ceramic Transactions Vol. 35); Moorhead, A.J., Leohman, R.E., Johnson, S.M., Eds.; The American Ceramic Society: Westerville, OH, USA, 1993; p. 43.

40. Okamoto, T. Interface structure of metal—Ceramic joints. ISIJ Int. 1990, 30, 1033-1040.

41. Martinelli, A.E.; Drew, R.A.L. Microstructural development during diffusion bonding of $\alpha$-silicon carbide to molybdenum. Mat. Sci. Eng. A 1995, 191, 239-247.

42. van Loo, F.J.J.; Rieck, G.D. Diffusion in the titanium-aluminium system-I. Interdiffusion between solid Al and Ti or Ti-Al alloys. Acta Metallurgica 1973, 21, 61-71.

43. Gutmanas, E.Y.; Gotman, I.; Kaysser, W. Coating of non-oxide ceramics by interaction with metal powders. Mat. Sci. Eng. A 1992, 57, 233-241.

44. Schiepers, R.C.J.; van Loo, F.J.J.; De With, G. The interaction between $\mathrm{SiC}$ and Ni, Fe, (Fe,Ni) and steel: Morphology and kinetics. J. Am. Ceram. Soc. 1988, 71, 211-218.

45. Naka, M.; Feng, J.C.; Schuster, J.C. Phase reaction and diffusion path of the SiC/Ti system Metall. Mater. Trans.1997, 28, 1385-1390.

46. Costa e Silva, A.; Kaufman, M.J. Phase Relations in the Mo-Si-C System Relevant to the Processing of $\mathrm{MoSi}_{2}-\mathrm{SiC}$ Composites. Metall. Mater. Trans. A 1994, 25, 5-15.

47. Schuster, R.C.; van Beek, J.A.; van Loo F.J.J.; De With, G. The interaction between SiC and Ni, $\mathrm{Fe},(\mathrm{Fe}, \mathrm{Ni})$ and steel: Morphology and kinetics. J. Europ. Ceram. Soc. 1993, 11, 211-218. 
48. Handbook of Ternary Alloy Phase Diagrams; Villars, P., Prince, A., Okamoto, H., Eds.; ASM International: Materials Park, Ohio, USA, 1995; p. 7370.

49. Gutmanas, E.Y.; Gotman, I. Coating of non-oxide ceramics by interaction with metal powders. Mater. Sci. Eng. A 1992, 157, 233-241.

50. Van Loo, F.J.J. Multiphase diffusion in binary and ternary solid-state systems. Prog. Solid St. Chem. 1990, 20, 47-99.

51. Kirkaldy, J.S.; Brown, L.C. Diffusion behavior in ternary multiphase systems. Can. Met. Quart. 1963, 2, 89-117.

52. Ward-Close, C.M.; Minor, R.; Doorbar, P.J. Intermetallic-matrix composites-a review. Intermetallics 1996, 4, 217-229.

53. Sakai, M.; Watanabe, K. Effect of pre-treatment and annealing temperature on the strength of SiCNi monofilament composites. J. Mater. Sci. 1984, 19, 3430-3436.

54. Everett, R.K.; Edelstein, A. S.; Perepezko, J.H. In situ-formed debond layer for fibers, US Patent 6376074, 2002.

55. van Loo, F.J.J.; Rieck, G.D. Diffusion in the titanium-aluminium system-I. Interdiffusion between solid Al and Ti or Ti-Al alloys. Acta Metall.1973, 21, 61-71.

56. van Loo, F.J.J.; Rieck, G.D. Diffusion in the titanium-aluminium system-II. Interdiffusion in the composition range between 25 and 100 at.\% Ti. Acta Metall.1973, 21, 73-84.

57. Hirano, K.; Iijima, Y. Diffusion in Solid : Recent Development; Dyananda, M.A., Murch, G.E., Eds.; Publ. of the Metall. Soc.: Materials Park, PA, USA, 1984; p. 141.

58. Cockeram, B.V.; Rapp, R.A. The kinetics of multilayered titanium-silicide coatings grown by the pack cementation method. Metall. Mater. Trans. A 1995, 26, 777-791.

59. Wagner, C. The evaluation of data obtained with diffusion couples of binary single-phase and multiphase systems. Acta Metall. 1969, 17, 99-107.

60. Munro, T.C.; Gleeson, B. The deposition of aluminide and silicide coatings on $\gamma$-TiAl using the halide-activated pack cementation method. Metall. Trans. A 1996, 27, 3761-3772.

61. Chou, T.C.; Neih, T.G. Solid state reactions between $\mathrm{Ni}_{3} \mathrm{Al}$ and SiC. J. Mater. Res, 1990, 5, 1985-1994.

62. Park, J.S. In situ Reaction Synthesis and Control during Interdiffusion; Ph.D. Thesis. Univ. of Wisconsin-Madison, Madison, WI, USA, 1998.

(C) 2010 by the authors; licensee Molecular Diversity Preservation International, Basel, Switzerland. This article is an open-access article distributed under the terms and conditions of the Creative Commons Attribution license (http://creativecommons.org/licenses/by/3.0/). 